\title{
Racial Inequality in the Prevalence, Degree, Extension, and Permeation of Incarceration in Family Life
}

\author{
Youngmin $\mathrm{Yi}^{1}$ \\ University of Massachusetts Amherst
}

\begin{abstract}
The prevalence, consequences, and unequal racial distribution of the experience of parental and own imprisonment have been well documented in scholarship on mass incarceration in the United States. However, much of our knowledge of the reach of mass incarceration into family life is focused on incarceration of a parent, romantic partner, or child, to the exclusion of other important relationships. Using data from a nationally representative survey of U.S. adults $(\mathrm{N}=2,029)$, this study introduces a set of new descriptive measures of family incarceration to provide a comprehensive picture of the demography of family incarceration and its unequal distribution across racial/ethnic groups: degree, generational extension, and permeation. The analysis shows that Black adults in the U.S. are not only more likely to have ever experienced family incarceration but are also likely to have had more family members incarcerated and to have had family members from more generations ever incarcerated than those of other racial and ethnic groups.
\end{abstract}

Keywords: family, incarceration, race, racial inequality, extended family, Family History of Incarceration Survey

${ }^{1}$ The author would like to thank Mariana Amorim, Megan Doherty Bea, Hedwig Lee, Jennifer Hickes Lundquist, and Christopher Wildeman for thoughtful feedback at earlier stages of this project. Please direct all correspondence to Youngmin Yi, 918 Thompson Hall, Department of Sociology, University of Massachusetts Amherst, Amherst, MA 02472, youngminyi@umass.edu. 


\section{INTRODUCTION}

In the United States (U.S.), incarceration is common, unequally distributed, and profoundly consequential (e.g., Pettit 2012; Wakefield and Uggen 2010; Western 2006). Nearly half of all residents of the U.S. have ever had an immediate family member incarcerated (Enns, et al. 2019). Those who are Black are substantially more likely than those of other racial/ethnic groups to have had a family member incarcerated (Enns, et al. 2019; Wildeman 2009) or to have been incarcerated themselves (Enns, et al. 2019; Pettit and Western 2004). Further, experiences of one's own incarceration and that of one's family members are linked to adverse outcomes in virtually all domains of social life at all stages of the life course (e.g., Foster and Hagan 2007; Wakefield and Wildeman 2014). These features of incarceration situate it as a core component of racial inequality and stratification in the U.S. (e.g., Alexander 2012; Roberts 2004; Wilson 1987; Wildeman and Muller 2012).

The central role of mass incarceration as part of the landscape of U.S. inequality includes its intersection with family life. Incarceration has the potential to put tremendous pressure on familial and other intimate ties, constraining social and financial resources (e.g., Bruns 2020; Green, et al. 2006), restructuring social roles and responsibilities (e.g., Braman 2004; Nurse 2002; Turney 2014), and adding logistical and emotional challenges to family relationships during and after incarceration (e.g., Comfort 2008; Gurusami 2019; Waller and Swisher 2006). Incarceration is also fundamentally linked to family life through its impacts on core demographic processes. For example, a limited, but growing, scholarship has explored whether and how incarceration and mass incarceration shape fertility (e.g., Cancian, Chung, and Meyer 2016); mortality (e.g., Pridemore 2014; Wildeman and Muller 2012); and family formation, structure, and instability (e.g., Sykes and Pettit 2014; Wildeman, Turney, and Yi 2016). 
However, the most prevalent approaches employed in scholarship on incarceration and families have two characteristics that limit our understanding of this "demography of family incarceration." First, prior work focuses nearly exclusively on the incarceration of parents and partners, privileging relationships prioritized in the white, upper middle-class construct of the nuclear family (e.g., Coontz 1992; Nelson 2014), to the exclusion of other relationships that may be equally or even more important to a person's social world (e.g., Amorim 2019; Eriksen and Gerstel 2002). ${ }^{2}$ Scholarship on variation in family relationships has found that Black and Hispanic parents and families, for example, are more likely than those who are white to be receiving social support from extended family members and to be living in extended-family households (e.g., Benin and Keith 1995; Cross 2018). This social patterning in the significance of extended family relationships (e.g., Ebaugh and Curry 2000; Moore 1990; Stack 1974) would also suggest that the consequences of having family members other than parents, children, or romantic partners may have an even greater negative impact in Black families, who are also at higher risk of criminal legal system involvement. The predominant focus on immediate family members in the study of mass incarceration may therefore produce an incomplete understanding of the impacts of this policy regime on Black families and communities, potentially underestimating racial inequalities in the reach of incarceration into family life and its consequences (Chung and Hepburn 2018; Lee, et al. 2015; Wildeman and Wakefield 2014).

A second limitation to analyses of family incarceration are their near-exclusive reliance on measures of prevalence (e.g., Enns, et al. 2019). Certainly, for capturing the reach of the carceral state, cumulative prevalence estimates of any family incarceration prior to the point of

\footnotetext{
${ }^{2}$ See Enns, et al. (2019) using FamHIS data and Chung and Hepburn (2018), Goldman (2020), Lee, et al. (2015), Meek (2008), Sirois (2020), and Wildeman and Wakefield 2014, and journalistic coverage in Lantingua-Williams (2016) for some key exceptions.
} 
data collection are improvements to point-in-time measures of ties to currently-incarcerated persons. However, prevalence measures effectively flatten experiences of family incarceration, unable to capture variation in the numbers of family members incarcerated, the generations of family impacted, and other ways in which families' carceral contact might differ.

This study uses nationally representative data from the Family History of Incarceration Study (FamHIS) to examine racial/ethnic inequalities in the depth and distribution of incarceration within families of adults in the U.S. I introduce three new descriptors of family incarceration to look beyond partners and parents and beyond prevalence: degree (number of family members), generational extension (horizontal, upward, or downward generation), and permeation (number of generations). This descriptive analysis sheds light on previouslyunexamined dimensions of inequality in family incarceration exposure: in addition to being more likely to experience family incarceration, Black adults experience substantially higher degree and greater permeation of incarceration throughout their family systems compared to adults of other racial/ethnic groups. Further, disparities between Black and non-Black adults in family incarceration prevalence, degree, generational extension, and permeation are statistically distinguishable even after accounting for correlates of family size, structure, and composition, and criminal legal system contact in the U.S.

\section{BACKGROUND}

In an era of persistently high rates and risks of incarceration in the U.S. (Walmsley 2018), researchers have detailed the reach of the carceral state into life beyond jail and prison walls (Braman 2004; Clear 2007; Lerman and Weaver 2014). This work focuses primarily on the incarceration of romantic partners, parents, and children of those ever incarcerated (e.g., Comfort 
2008; Foster and Hagan 2015; Wildeman 2009; Wildeman and Wakefield 2014) and has found that the incarceration of any of these relations has the potential to fundamentally shape the tempo, structure, and tenor of daily life and family process (e.g., Arditti, Lambert-Shute, and Joest 2003; Christian 2005; Comfort 2008, 2016).

Partner, parent, and child incarceration have also been estimated to be consistently and negatively associated with measures of wellbeing across virtually all domains of life and over the life course (e.g., Arditti 2012; Foster and Hagan 2015; Wildeman, Goldman, and Turney 2018). Evidence shows that incarceration of these familial relations is associated with lower levels of academic engagement and attainment in childhood (e.g., Cho 2009; Hagan and Foster 2012; Haskins 2014), higher risks of relationship conflict and instability (e.g., Turney 2014, 2015), infant mortality (e.g., Wildeman 2012), and poor adult health (e.g., Lee, et al. 2014), among many other adverse experiences and outcomes (Wakefield and Uggen 2010). The racially unequal distribution of partner, parent, and child incarceration across the population, coupled with these substantial and multifaceted negative associations, positions incarceration as a core component of racial and family inequality in the U.S. (e.g., Pattillo, Western, and Weiman 2004; Wildeman and Wang 2017)

\section{Beyond Partners, Parents, and Prevalence}

However, there are some critical limitations to our current empirical understanding of family incarceration in the United States. First, the scholarship is constrained by its focus on social relationships often construed to be most salient to one's daily life - namely romantic partners, children, and parents (Wildeman and Muller 2012). So far, this limited view of the family, combined with the absence of appropriate quantitative data, have made it difficult or 
impossible to detail the incarceration of those considered beyond the immediate familial sphere. ${ }^{3}$ The focus on biological proximity ultimately privileges normative family forms and relationships that are predominantly held by the white middle-to-upper class of the U.S. (Coontz 1992; Roberts 2002). In so doing, prior analyses take a prescriptive approach, whether explicitly or inadvertently, defining the relationships that would be most consequential for those "left behind," if those particular relations were to be held behind jail or prison walls.

However, relationships with family members other than partners, parents, and children are also important correlates of social, economic, and health outcomes over the life course (e.g., Cross 2020; Hall and Crowder 2011; Turney 2014; Youngblut, et al. 2015). Siblings, for example, shape one another's social and emotional wellbeing in childhood and adolescence and go on to serve as sources of social and material support in adulthood and later life (Brody 1998; Connidis and Campbell 1995; Heflin and Pattillo 2006; White and Riedmann 1992). Grandparents and other relations — particularly grandmothers and aunts — often serve as primary or secondary caregivers to children and as other critical sources of social and in-kind support in families (e.g., Gerstel 2011; Jaeger 2012). Additionally, prior work documenting variation in family and social support networks across racial/ethnic groups and family types (e.g., single parent families) finds that people who are more likely to have extended and other family relations centrally involved in their day-to-day lives (e.g., Sarkisian 2007; Sarkisian and Gerstel 2012) are also of the same social groups that are disproportionately likely to experience family member incarceration (Enns, et al. 2019). Disruption and strain in family relationships related to

\footnotetext{
${ }^{3}$ This point is also made in other work, including Chung and Hepburn (2018), Enns and colleagues (2019); Lee and colleagues (2014).
} 
family member incarceration could therefore be related to inequality in at least two ways: through unequal distribution and unequal impact.

Further, recent estimates show that the incarceration of family members other than partners, parents, and children, are quite common. Indeed, prior estimates show that the experience of sibling incarceration (27\%) is 1.5 times to twice as common as parental (18\%), child (12\%), or partner incarceration (14\%) (Enns, et al. 2019). Analysis of these other types of family member incarceration finds that these experiences are, too, unequally distributed, with those identifying as Black disproportionately and substantially more likely to be impacted (Chung and Hepburn 2018; Enns, et al. 2019). To date, many analyses capable of incorporating information about extended familial relations' incarceration have done so in an attempt to account for "family effects" on criminality that may be predictive of one's own contact with the criminal legal system rather than an example of such contact (e.g., Besemer, van de Weijer, and Dennison 2018; Buhller, et al. 2018; Harding, Morenoff, Nguyen, and Bushway 2017; Norris, Pecenco, and Weaver 2021).

A second limitation to our current understanding of family incarceration in the U.S. is the focus to date on the prevalence of family incarceration, and particularly, as noted above, the prevalence of partner, parental, and child incarceration. This focus on prevalence may mask other important differences and inequalities in family incarceration risk and exposure. Just as families vary in size, structure, and composition (e.g., Perkins 2017; Pilkauskas and Cross 2018; Cross 2018; Swartz 2009; Fomby and Cherlin 2017), the structure and distribution of incarceration within families likely varies in important ways, as well.

To illustrate the impact of these limitations on existing empirical descriptions of family incarceration and disparities therein, we can use an example. Consider two hypothetical 
individuals, one whose father was incarcerated and a second whose father, sibling, and aunt have all been incarcerated at some point. The most common contemporary approaches to studying family member incarceration would capture the fact that both adults have had a family member incarcerated, but not differences in the number of family members ever incarcerated or differences in the types of relationships affected. Indeed, prior approaches to studying family incarceration that focus on immediate family relationships — specifically partners, parents, and children — would fail to capture the incarceration of the aunt in this example entirely.

Without a more comprehensive understanding of the configuration of incarceration exposure within families and how these vary across racial/ethnic groups (or not), description and analysis of family member incarceration are susceptible to oversimplification of the experience and potentially misidentification of associated outcomes and effects of carceral contact. More specifically, without a better handle on the heterogeneity of family incarceration, the experience of having one relation incarcerated is conceptualized and operationalized as similar in effect or as a similar "treatment" as the experience of having had multiple generations of a family experience someone's incarceration.

\section{Detailing Family Incarceration: Social Network and Family Demographic Approaches}

In this study, I examine racial/ethnic inequality in exposure to family member incarceration using measures beyond prevalence, conceptual tools commonly leveraged in family demographic and social network analyses are especially useful. The family is, in fact, a social network (e.g., Bott 1957; Stack 1974; Chung and Hepburn 2018), one that has legal, cultural, and sociopolitical definitions. The conceptualization of families as social networks and incarceration as a shock that moves through them, has been essential to our contemporary understanding of incarceration as a mechanism of inequality in the U.S. (e.g., Haynie, et al. 2018; Mowen and 
Visher 2016; Wakefield 2016). Here, I provide new detail about family incarceration in the U.S. and racial/ethnic inequalities therein by combining family demographic tools, a social network perspective on the family, and the study of the effects of mass incarceration on family life. To do so, I describe family incarceration using measures of the prevalence, degree (number of family members), generational extension (same, older, or younger generation), and permeation (number of generations) of family member incarceration in the families of adults in the U.S., with a specific focus on racial/ethnic inequality. I use regression analysis to account for variation in family and life course contexts (e.g., parental status) and other socioeconomic and demographic characteristics and contexts that are correlates of exposure to family incarceration.

Given the racialized history of the criminal legal system in the U.S. (Beckett and Western 2001; Miller 2013; Muller 2012; Thompson 2020), I anticipate that more detailed descriptors of family incarceration that examine incarceration through generations and different relation types will reveal previously unexamined racial disparities in family incarceration that prevalence measures are not designed to capture. Indeed, prevalence estimates may mask other critical dimensions of inequality related to family incarceration, namely the profundity and intensity with which incarceration reverberates through an individual's family system.

Existing knowledge of family and household diversity, however, points towards multiple plausible hypotheses about racial/ethnic differences in family member incarceration. It is possible that accounting for dimensions of social variation related to, but not wholly distinct from, race and racism in the U.S. might help us understand differential exposure to family incarceration. On the other hand, it is possible that because social organization in the U.S. are so profoundly racialized that any differences in family member incarceration across racial/ethnic 
groups are not further clarified by incorporating information about other dimensions of social life linked to family form and process or criminal legal system contact.

\section{DATA, MEASURES, AND METHODS}

\section{The Family History of Incarceration (FamHIS) Study}

This analysis uses data from the Family History of Incarceration Study (FamHIS), a nationally representative survey of non-institutionalized adults residing in the U.S. in 2019. These data were the basis for the first-ever estimates of the cumulative risk family incarceration for U.S. adults (Enns, et al. 2018; Enns, et al. 2019). The FamHIS is based on the AmeriSpeak panel operated by the National Opinion Research Center (NORC) at the University of Chicago (NORC 2019), and has features that make it a uniquely suitable data source for studying family criminal legal system contact at a national scale. The FamHIS sample is a nationally representative probability-based sample drawn from a respondent panel that oversamples adults from age and racial/ethnic groups often underrepresented in survey data (Dennis 2016). Additionally, the FamHIS survey was administered in both English and Spanish and through web and phone response options, mitigating potential threats to data quality stemming from nonresponse and social desirability bias (Dennis 2016). Finally, the FamHIS survey instrument includes a set of roster-based items that collect unprecedented detail about family member incarceration that respondents experienced at or before the time of survey.

The FamHIS survey opens with a screening tool that asked a baseline sample of 4,041 respondents recruited from the NORC AmeriSpeak panel whether they had ever had any immediate family members incarcerated in a jail or prison for at least one night, as well as the relation type of those ever-incarcerated family members. At the conclusion of this screening 
module, all 1,808 respondents who reported any immediate family incarceration and a random sample of 1,009 of the remaining 2,233 respondents who did not report any immediate family incarceration were recruited to participate in the rest of the survey, which goes on to ask about the jail and prison incarceration of any extended family members as well as respondents' own criminal legal system contact. Of these 2,817 FamHIS respondents (70\% of all 4,041 FamHIS screener respondents) who were recruited into the full survey and therefore asked about both immediate family incarceration in the screening module and extended family incarceration in the remainder of the survey, I restricted the analytic sample further to exclude individuals who were missing information necessary for the analysis. I excluded respondents who were not assigned sampling weights because they skipped nearly the full survey instrument $(\mathrm{N}=2)$ (Enns, et al. $2019,2)$, who did not respond to survey items inquiring about family incarceration $(\mathrm{N}=768)$, and those who were missing information on any of the sociodemographic measures included in the regression analyses $(\mathrm{N}=18) .^{4}$

These constraints yield a final analytic sample of 2,029 respondents. A description of the analytic sample and comparison to the national population are presented in Table 1 . The respondents whose experiences are reflected in this article have characteristics that are nearly identical to those of the non-institutionalized U.S. adult population as described by population benchmark data, illustrating the representativeness of the respondents included in my analysis. The sole observed difference between the analytic sample and comparison data on the national population is in the distribution of respondents across metropolitan and non-metropolitan areas. In the analytic sample, the majority of respondents were from metropolitan areas $(88 \%)$, whereas

\footnotetext{
${ }^{4} 21$ of the excluded respondents were missing information on both family member incarceration and sociodemographic measures included in the regression analyses.
} 
in the comparison data, 42 percent of adults live in metropolitan areas. Supplementary analyses that impute missing information for the 786 of the 2,815 respondents sampled into the full survey but excluded from the analysis show that the imputed sample is nearly identical to the analytic sample that I use; a comparison of characteristics of the full FamHIS sample, the analytic sample used here, and the imputed sample is presented in Appendix Table 1.

\section{Family Incarceration}

The FamHIS survey enumerates whether the respondent has ever had a family member incarcerated for more than one night, by family member type using the following categories: mother, father, brother, sister, son, daughter, spouse/romantic partner, non-partner parent of children, aunt/uncle, cousin, grandparent, grandchild, niece/nephew, parent-in-law, sibling-inlaw, and other family. The survey also asks respondents if they themselves have ever been incarcerated for at least one night. Using this detailed information, I am able to provide detailed information about U.S. adults' exposure to family incarceration, which I describe using measures of the prevalence of family incarceration, previously estimated in other work using the FamHIS (Enns, et al. 2019; Sundaresh, et al. 2020), as well as three new descriptors of family incarceration: degree, generational extension, and permeation.

The set of three measures describing the prevalence of family member incarceration indicates whether a respondent reports ever having had an immediate, extended, and any (immediate or extended) family member incarcerated for more than a day, using a separate prevalence measure for each type of family member incarceration. To provide further insight into variation in the intensity of exposure to family incarceration, I also construct and use a measure of the degree of family member incarceration. Drawn from social network methods, the term "degree" refers to the total number of relations or social network ties a particular individual or 
social unit has (Wasserman and Faust 2009, 100). Here, degree is conceptualized as a tie to the carceral state and measured as one's total number of family members ever incarcerated for at least one night, reporting totals for immediate, extended, and any family member.

To explore variation in the structure of family member incarceration through families, I use two additional measures: generational extension and permeation. The term "generational extension" borrows language from family demography that is used to describe the addition of non-immediate family relations into a living arrangement or household (e.g., Angel and Tienda 1982; Glick, Bean, and Van Hook 1992; Sarkisian, Gerena, and Gerstel 2007). Generational extension of family incarceration is captured using a set of three dichotomous measures of horizontal extension, or the incarceration of any family members of the same generation as the respondent (sibling, cousin, sibling-in-law, spouse/romantic/partner, co-parent); downward extension, or the incarceration of anyone who is of the generation younger than or below the respondent (child, niece/nephew, grandchild); and upward extension, which includes anyone who is of a generation older or above the respondent (parent, aunt/uncle, parent-in-law, grandparent, godparent).

Finally, permeation of family incarceration reports the number of generations in a respondents' family that have had any incarceration, with respondents' own incarceration included as part of this measure. As described earlier in this section, the FamHIS measures of family incarceration by family member type include 16 family relation types; these relational categories span up to five generations of a respondent's family, extending two generations below the respondent (i.e., grandchild) to two generations above the respondent (grandparent). Therefore, my measure of family incarceration permeation ranges from a minimum of zero generations (no family members ever incarcerated) to a maximum of five generations (family 
members incarcerated in two generations below, in two generations above the respondent, and in the same generation as the respondent).

\section{Respondent Characteristics and Contexts}

This article seeks to expand our understanding of racial/ethnic inequality in family incarceration. To this end, a key measure for this analysis is that of respondent racelethnicity. The FamHIS' two measures of race/ethnicity use six mutually exclusive categories in one measure (Asian, Black, Hispanic, other, white, and two or more racial/ethnic groups) and five mutually exclusive categories in the other (American Indian/Alaskan Native, Black, Hispanic, other, white). This analysis combines both measures, ultimately drawing on a mutually exclusive set of four categories of self-identified race and ethnicity: Black, Hispanic, white, and multiracial or other racial/ethnic group). Further disaggregation was not possible due to small cell sizes that rendered models inestimable.

An individual's exposure to family incarceration is shaped, in part, by the life course experiences that impact their family ties, structures, and living arrangements. For example, the likelihood of experiencing a spouse's incarceration is directly linked to whether one has ever been married. As such, the models account for measures of life course experiences and contexts that shape an individual's family and household relationships, and therefore, the number and, to some extent, types of family members potentially incarcerated. These covariates are continuous measures of respondents' age (years) and household size (number of persons in household); a categorical measure of partnership history/status (previously married and not living with a spouse/partner, living with a spouse/partner, never married and not living with a spouse/partner); 
a dichotomous measure of parental status that reports whether the respondent has any children; and a dichotomous measure of nativity (born inside or outside of the U.S.). ${ }^{5}$

Family life and risks of criminal justice system contact are also highly gendered (Braman 2004; Daly 1989). Women are slightly more likely to have ever had any immediate family members incarcerated (Enns, et al. 2019). Women are also often tasked with the work of maintaining familial ties while loved ones are held behind bars and supporting family members as they transition back into civilian life upon their release (Arditti, Lambert-Shute, and Joest 2003; Braman 2004; Comfort 2008). The analysis therefore includes a dichotomous measure of respondent gender noting whether the respondent identifies as male or female. ${ }^{6}$

Risks of criminal legal system contact also vary spatially, with uneven risks of imprisonment and parental imprisonments across U.S. regions (Muller and Wildeman 2016) and variable trends in incarceration and expansion of carceral facilities across rural and urban space (Eason 2017; Kang-Brown and Subramanian 2017). As such, the models also account for respondents' region of residence (Northeast, Midwest, South, West) and a dichotomous indicator of whether the respondent lives in a metropolitan area. Finally, socioeconomic contexts are strong correlates of contact with the criminal legal system (Pettit and Western 2004; Western and Muller 2013; Wildeman 2009). Therefore, the analysis also uses categorical measures of respondents' educational attainment (no high school degree/equivalent, high school degree or

\footnotetext{
${ }^{5}$ The FamHIS data also include family roster items that could presumably be used to account explicitly for respondents' varying family size. However, examination of the data indicate that those measures do not consistently or accurately describe the size of respondents' families. For example, respondents sometimes reported having no family members of a certain type but then reported having had family members of that type incarcerated. Therefore, I have chosen not to use those measures.

${ }^{6}$ Although this conflates gender identification with categories used to describe sex, rather than gender, I use this terminology to be consistent with the language used in the FamHIS survey instrument and its accompanying documentation.
} 
equivalent credential, some college, Bachelor's degree or further education) and household income (\$0-\$24,999; \$25,000-\$49,999; \$50,000-\$74,000; \$75,000-\$99,999; \$100,000 and more).

\section{Analytical Approach}

This comprehensive descriptive analysis begins with a statistical summary of the family incarceration exposure of non-institutionalized adults in the U.S. I then proceed by estimating four nested regression models that examine racial/ethnic differences in the prevalence, degree, generational extension, and permeation of family incarceration, accounting for increasingly comprehensive sets of measures of characteristics and contexts that might also be predictive of one's exposure to family incarceration. The regression analyses begin by estimating characteristics of family incarceration exposure as functions of only respondents' race/ethnicity (Model 1). The three subsequent specifications account additionally for respondents' life course characteristics (Model 2), geographic context (Model 3), and socioeconomic context (Model 4), with discussion of the results of all of these models focusing on family member incarceration across racial/ethnic groups. Variation with respect to social characteristics and contexts often treated as independent from race— such as socioeconomic status, marital status, and residential context — are themselves components of racialized life and racism (e.g., Faber 2020; Ray 2019; Sewell 2016; Williams and Collins 1995). These regression adjustments, rather than "controlling away" relevant predictors of family member incarceration, instead situate this analysis in relation to the broader scholarship investigating race and incarceration in the U.S.

Associations between racial/ethnic group and prevalence and generational extension of family incarceration are estimated using logistic regression models to account for the binary form of those measures. Models for the continuous measure of degree of family incarceration are specified as linear regressions and for the count measure of permeation of family incarceration as 
Poisson regressions. All models are weighted using sampling weights that account for the sampling design of the FamHIS and unequal eligibility for participation in the full FamHIS survey instrument and benchmark the FamHIS sample to the U.S. non-institutionalized adult population. Supplementary unweighted analyses yield substantively similar conclusions, though with larger estimated magnitudes of racial/ethnic disparities.

\section{RESULTS}

The statistical snapshot presented in Table 2 present unadjusted estimates of the average characteristics of family incarceration exposure in the analytic sample, overall and by broad racial/ethnic group. The estimates show that 40 percent of adults have ever had an immediate family member incarcerated, 34 percent have ever had an extended family member incarcerated, and over half of adults in the U.S. have ever had an immediate or extended family member incarcerated (52\%). On average, U.S. adults have had between two and three family members incarcerated for at least one night and horizontal (same-generation) family member incarceration is the most commonly experienced of the three possible types of generational extension of family incarceration (44\% vs. $30 \%$ with upward extension and $19 \%$ with downward extension).

Across all four descriptors of exposure to family incarceration examined, adults who identify as Black are substantially more likely to experience both immediate and extended family incarceration and likely to experience more intensive or concentrated exposure to family incarceration than those of other racial/ethnic groups. For example, on average, white respondents report having 0.99 immediate and 1.53 extended family members ever incarcerated, while those numbers are over twice as high among those who identify as Black (2.11 immediate and 3.20 extended family members). 
[Table 2 about here]

The unadjusted statistical descriptions of the prevalence, degree, generational extension, and permeation of incarceration in families in the U.S. provide a detailed empirical illustration of the reach of the incarceration and racial/ethnic inequality therein. My analysis now turns to a series of nested multivariate regression models to further explore the racialized nature of incarceration in U.S. family life. These models allow for a comparison of race/ethnicity-specific estimates of the prevalence, degree, generational extension, and permeation of family incarceration after adjusting for measures of variation in other sociodemographic characteristics, life course experiences, and geographic and socioeconomic contexts that have been previously identified as correlates of family diversity and criminal legal system involvement. The results of these models are presented in Figures 1-4, Table 3, and Appendix Tables 2-4.

\section{Prevalence of Family Incarceration}

Estimated associations from models that only incorporate information about respondents' race/ethnicity (Model 1) show great variation in the prevalence of immediate, extended, and any family member incarceration across racial/ethnic groups (Table 3 and Fig. 1). Models 2-4, although incorporating substantially more detail about respondents' characteristics and social contexts, tell a story that is nearly identical to that of the baseline model. Indeed, even after adjusting additionally for measures that describe respondents' life course characteristics (age, gender, parental status, partnership/cohabitation history and status, and household size) (Model

2), spatial context (region, metropolitan area) (Model 3), and socioeconomic context (educational attainment, household income) (Model 4), the racial/ethnic disparities estimated in Model 1 remain statistically distinguishable and stable in magnitude across specifications (Table 3). 
According to estimates from the fully adjusted models (Model 4), those who identify as Black are substantially more likely than adults of all other racial/ethnic groups to have experienced the incarceration of a family member, whether focusing on immediate family only, extended, family only, or both immediate and extended family. 60 percent of Black adults have experienced an immediate family member's incarceration, $53 \%$ have experienced an extended family member's incarceration, and $74 \%$ have experienced either one of those events.

Alongside this stark Black-non-Black disparity, it is also notable that more than one-third of adults in all racial/ethnic groups have experienced immediate family incarceration and at least $31 \%$ of adults in all groups have experienced extended family incarceration (Table 3, Model 4 and Fig. 1). Those identifying as Asian, Native American, Alaskan Native, or of another racial/ethnic group, combined in the other race category due to prohibitively small cell sizes, have the lowest predicted probabilities of immediate (33\%), extended (31\%), and any family member incarceration (44\%). However, these estimates should be interpreted with caution. Prevalence estimates for those in the other race category are not statistically distinguishable from those describing the experiences of white adults or adults of Hispanic ethnicity and represent an aggregation of persons identifying with racial/ethnic groups that have distinct histories and contemporary contexts of contact with the criminal legal system (e.g., Hall and Simkus 1975; Franklin 2013).

[Table 3 about here]

[Fig. 1 about here]

\section{Degree of Family Incarceration}

Prevalence is only one way to measure the reach and impact of incarceration on families and the degree to which this varies across racial/ethnic groups. The next set of models estimate 
associations between race/ethnicity and degree, or the number of immediate, extended, and any immediate or extended family members ever incarcerated for at least one night. Models that only adjust for respondents' race/ethnicity reveal substantial racial disparities in the degree of family member incarceration exposure. Again, these estimates remarkably stable in precision and magnitude with additional adjustments to account for other known correlates and predictors of criminal legal system contact and family structure and composition (Appendix Table 2). As this is true for all subsequent analyses, the remaining discussion of results focuses on estimated associations from the fully adjusted models, with full results presented in tabular form in Appendix Tables 2-4. As shown in Figure 2, the fully adjusted models estimate that, on average, adults in the U.S. have had one immediate family member incarcerated, 1.5 extended family members incarcerated, and over two family members of any relation incarcerated ( 2.5 persons).

Turning now to race/ethnicity-specific estimates, the importance of looking beyond prevalence when thinking of carceral contact in family life is immediately evident. This descriptor of family member incarceration allows us to see that in addition to being substantially more likely to ever having had a family member incarcerated, Black adults in the U.S. are likely to have had a higher degree of family incarceration, or a greater number of family members who have ever been incarcerated. This is true even after adjusting for characteristics that are mechanically associated with family size, such as parental and partnership status, that shape the "risk pool" of family members who could have been incarcerated (Fig. 2).

On average, white adults have had 0.75 immediate family members incarcerated, 1.17 extended family members incarcerated, and 1.92 immediate or extended family members incarcerated. Among those identifying as being of Hispanic ethnicity, adults have had 1.12 immediate family members incarcerated, 1.68 extended family members incarcerated, and 2.80 
family members of any relation incarcerated, although these estimates were not statistically distinguishable from those for respondents in the other racial/ethnic group. Again, Black adults' experiences contrast sharply with experiences of adults in all other racial/ethnic groups: on average, Black adults have had over 2 immediate family members incarcerated, 3.20 extended family members incarcerated, and 5.30 family members of any relation incarcerated.

\section{[Fig. 2]}

\section{Generational Extension of Family Incarceration}

Taking a demographic perspective, we can also consider the possibility of variation in the structure or distribution of incarceration within family systems. Here, this is first captured in my analysis through descriptors of the generational extension of family incarceration: horizontal, or same-generation (e.g., cousin); upward, or earlier/older-generation (e.g., aunt); and downward, or later/younger-generation family incarceration (e.g., grandchild). Estimated adjusted associations between race/ethnicity and this dimension of family incarceration are presented in Figure 3 and Appendix Table 3. The full models show that horizontal family incarceration-the incarceration of siblings, cousins, or romantic partners—is the most commonly experienced direction of generational extension of family incarceration reported by all adults. Overall, $44 \%$ of adults have experienced family incarceration through horizontal extension, $30 \%$ through upward extension, and 19\% through downward extension across generations.

Family incarceration through horizontal extension is also the most prevalent type of generational extension of family incarceration experienced for adults who are Black, in the other racial/ethnic group, or white. However, again, these group-specific estimates reveal substantial and statistically distinguishable differences across racial/ethnic groups that remain essentially constant across models. In the fully adjusted model, two-thirds of Black adults (66\%) had ever 
experienced family incarceration through horizontal extension, substantially and statistically distinguishably shares higher than the corresponding adjusted proportion for white adults (39\%). Among adults of Hispanic ethnicity, 49 percent have experienced family incarceration through horizontal extension, but this proportion is not statistically distinguishable from the proportion of Hispanic adults who have experienced family incarceration through upward extension (49\% $[95 \% \mathrm{CI}=40 \%, 58 \%]$ vs. $34 \%[95 \% \mathrm{CI}=26 \%, 42 \%])$.

Proportions of those reporting upward and downward family incarceration are somewhat lower, although still sizable. Upward family incarceration is the next most commonlyexperienced generational extension of family incarceration for all racial/ethnic groups. Nearly half of Black respondents (49\%) reported experiencing upward family incarceration, along with $34 \%$ of Hispanic adults, $31 \%$ of adults in the other racial/ethnic group, and $26 \%$ of white adults. Differences between estimates for Black adults and adults identifying as white or of the other racial/ethnic groups are statistically distinguishable. Other pairwise comparisons do not reveal statistically distinguishable racial/ethnic differences.

Finally, downward family incarceration is the least prevalent type of generational extension of family incarceration for all racial/ethnic groups, but, again, substantially and statistically distinguishably more common for those identifying as Black than for adults in the other three racial/ethnic categories. 18 percent of white adults, $14 \%$ of Hispanic adults, $13 \%$ of those in the other racial/ethnic group, and over one-third of Black adults (34\%) report having had a child, nephew/niece, grandchild, or godchild incarcerated.

[Fig. 3]

\section{Permeation of Family Incarceration}


Finally, to further detail and examine the reach of family, I estimate associations between racial/ethnic group and the permeation of family incarceration through family systems, measured as the number of generations of family members a respondent has ever had incarcerated. These results are presented in Figure 4 and Appendix Table 4. Consistent with the demographic picture of the racialized nature of carceral contact assembled so far, family incarceration permeates deeper into the families of Black adults than families of Hispanic, other race/ethnicity, and white adults in this analysis. The fully adjusted models show that Black adults have had an average of 1.72 generations with any family members ever incarcerated, a statistically higher number of generations than those who are Hispanic (1.10 generation), in the other racial/ethnic category (0.95 generations), or white (0.93 generations). No other pairwise comparisons in the permeation of family incarceration revealed statistically distinguishable differences (Fig. 4).

[Fig. 4]

\section{DISCUSSION}

Unequal risks of contact with the criminal legal system in the U.S. and the linkages between incarceration and wellbeing are now well-documented (Foster and Hagan 2015; Massoglia and Pridemore 2015; Wakefield and Uggen 2010). However, without a more detailed picture of the demography of family incarceration, we run the risk of underestimating the reach of mass incarceration (Enns, et al. 2019), its unequal effects on family life, and the potential impact of policies that focus on lowering incarceration rates and the number of people currently incarcerated (Chung and Hepburn 2018; Wildeman and Wakefield 2014). Taken together, the results of my investigation of the demography of family incarceration provides new detail about racial/ethnic inequality in carceral contact in the U.S., which I summarize in three concluding 
points. First, unadjusted estimates show that family member incarceration is not only prevalent (Enns, et al. 2019), but also deeply embedded through families in the U.S. A noninstitutionalized adult in the U.S. has had an average of 2.52 family members ever incarcerated and 1.06 generations in which a family member has ever been incarcerated.

Second, Black adults' likelihood of family incarceration and the degree, generational extension, and permeation of incarceration through their families far exceed those of other racial/ethnic groups. On average, a Black adult in the U.S. has had 5.30 family members incarcerated and 1.72 generations with family members who have experienced incarceration. Third, estimated racial/ethnic inequalities in the degree, generational extension, and permeation of incarceration do not change with the incorporation of additional information about adults' characteristics and contexts. There is a tendency to interpret analyses of racial/ethnic differences that incorporate information about characteristics and contexts correlated with race as "controlling" for differences to create a race-neutral vacuum for analysis (e.g., Gillborn, Wilmington, and Demack 2018; Stewart 2008, pp.116-119). However, the striking stability in the estimated racial/ethnic disparities in family incarceration exposure observed across the models presented in this paper provide additional evidence of the overwhelming salience of race for criminal legal system contact and the inextricably racialized nature of sociodemographic and economic contexts (e.g., Ray 2019; Sewell 2016).

These estimates are faced with some limitations, some of which are shared challenges in survey research on institutional contact and race/ethnicity more broadly (e.g., Geller, Jaeger, and Pace 2016; Pettit 2012). First, the underrepresentation of U.S. adults living in non-metropolitan areas in my analysis could mean that these estimates are biased, although it is not clear whether that implies overestimation or underestimation of the prevalence, degree, generational extension, 
and permeation of family incarceration and racial disparities therein. Recent expansion of incarceration in rural places (Eason 2017; Kang-Brown and Subramanian 2017), mean that the estimates presented here potentially underestimate family member incarceration. This could be all the truer for adults of Hispanic ethnicity who are more likely to be subjected to surveillance and detention related to immigration enforcement, one driver of the expansion of carceral policy and practice across the U.S. (Arriaga 2017; Meissner, et al. 2013; Menjivar, Cervantes, and Alvord 2018; Pickett 2016; National Research Council 2014, pp. 61-64). Second, my inability to produce estimates of the demography of family incarceration for Asian/Pacific Islander and Native American persons due to prohibitively small cell sizes is a major limitation. The group of persons identified as being of another racial/ethnic group (see "other" in Table 1, for example) combines racial/ethnic groups with starkly different histories of contact with the carceral state (Beckett and Evans 2015; Hall and Simkus 1975; Franklin 2013; Madley 2019).

Further, the FamHIS data are nationally representative of U.S. adults in households, meaning that the FamHIS sample, like much other survey data, systematically misses those who are institutionalized, including incarcerated adults (Pettit 2012). Evidence of the clustering of carceral contact in the U.S. shown here and in some prior work (Lee, et al. 2015; Wildeman and Wakefield 2014) suggests that those not represented in these analyses due to this feature of the FamHIS may be more likely to have ever-incarcerated family members than the population of adults who are not institutionalized. This would mean that here, I potentially underestimate adults' family incarceration and racial/ethnic inequality in carceral contact in the U.S.

Finally, I cannot be certain that respondents considered all family members, living or deceased, co-resident or living elsewhere, in answering the FamHIS survey items about family member incarceration. Although it is likely that respondents were able to report on the 
incarceration experiences of their most salient or close family members, the measures of family that I analyze, even though broadly construed, may not capture incarceration of more distant family members. Relatedly, as extended family networks are generally larger than immediate family networks, the finding that the prevalence of immediate family member incarceration is greater than that of extended family member incarceration is somewhat surprising ( $44 \%$ vs. $35 \%)$. This may be due to respondents' lower likelihoods of knowledge of more distant relations' incarceration histories. Additionally, the FamHIS survey may have missed other people who are significant in respondents' lives but are not labeled as family members, such as friends, coworkers, neighbors, and mentors (e.g., Braman 2004; Clear 2007).

A look beyond the scope of this analysis highlights important areas and considerations for future investigation, particularly that which focuses on incarceration effects. The substantial racial heterogeneity and inequality in family incarceration identified in this analysis lead to questions about whether there is also variation in the impact of incarceration across types of family members and significant others incarcerated. For example, is the incarceration of a parent necessarily more disruptive or otherwise consequential for one's wellbeing than the incarceration of other close ties such as a friend, sibling, or aunt? Future work that is able to build on the indices of variation in family incarceration that I have introduced in this study is likely to be fruitful for other investigations of state involvement in family life. Some examples of existing tools that could be leveraged include social network measures of the variable significance of social ties (e.g. valued graphs and relations, Wasserman and Faust 1994, 140-143) (Burt 1984; Marsden 1987; Wellman and Wortley 1990); household, family, and social network rosters in survey data that provide information on co-residence and relationship types (Marsden 1987; Tach and Cornwell 2015) such as the rosters in the National Longitudinal Survey of Youth 
(Bureau of Labor Statistics 1997-2017); and social psychological measures that aim to capture varying quality and conditions of social relationships (Bearman and Parigi 2004; Brashears 2014) such as those in the National Longitudinal Study of Adolescent to Adult Health (e.g., frequency of interaction, physical proximity, affective closeness; Harris 2009).

A second proposed area for investigation that stems from these findings is more epistemic in nature and interrogates the approaches we use to study the relationships between race/ethnicity, family, and contact with the criminal legal system in the U.S. The inferential strength and validity of estimated effects of own and family incarceration and local incarceration rates are often evaluated as hinging on analysts' ability to account for selection (Wakefield and Uggen 2010; Wildeman 2020). ${ }^{7}$ This requires analyses to control for characteristics and contexts conceptualized as related but distinct, and often includes the use of measures of individual racial/ethnic identity or racial/ethnic composition of populations in geographic units of study. However, the estimates presented here illustrate the strong associations of individuals' racial/ethnic identity with the prevalence, degree, generational extension, and permeation of family incarceration. This new level of detail about the racialized demography of family incarceration provides additional reason to interrogate the practice of controlling or adjusting away racial/ethnic identity in analysis and interpretation of the carceral state, its form, function, and consequences. What does it mean when the practice of attempting estimation of individuallevel effects of incarceration "net of" race/ethnicity and one's family's stable characteristics may ultimately control away salient disparities in family incarceration such as those captured in the

\footnotetext{
${ }^{7}$ An in-depth discussion of research designs used for causal inference of family incarceration effects is beyond the scope of this paper. See work by Billings (2019), Cho (2009), Dobbie (2018), and Norris and colleagues (2021), for examples of causal analysis of family incarceration effects.
} 
current study? What does it mean to model community and population-level wellbeing as functions of incarceration rates by "controlling for" racial/ethnic composition, when the degree, generational extension, and permeation of incarceration are so much more severe in Black families than for families of other racial/ethnic groups?

This analysis details the first nationally representative picture of the demographic characteristics and structuration of family incarceration in the U.S. In so doing, I provide new population-level insight into the multifaceted racial/ethnic inequality at the intersection of carceral and family life. In addition to confirming the disproportionate salience of incarceration for Black lives in the U.S. identified previously (Alexander 2012; Enns, et al. 2018; Roberts 2004; Wildeman 2009), these estimates provide new measures and information about the unequal and racialized creep of the carceral system into family life and family histories. 


\section{REFERENCES}

Alexander, M. (2012). The new Jim Crow: Incarceration in the age of colorblindness. New York: The New Press.

Amorim, M. (2019). Are grandparents a blessing or a burden? Multigenerational coresidence and child-related spending. Soc. Sci. Res. 80:132-144.

Angel, R., \& Tienda, M. 1982. Determinants of extended household structure: Cultural pattern or economic need? Am. J. Sociol. 87(6), 1360-1383.

Arditti, J. A. (2012). Child trauma within the context of parental incarceration: A family process perspective. J. Fam. Theory Rev. 4(3), 181-219.

Arditti, J. A., Lambert-Shute, J., Joest, K. (2003). Saturday morning at the jail: Implications of incarceration for families and children. Fam. Relat. 52(3), 195-204.

Arriaga, F. (2017). Relationships between the public and crimmigration entities in North Carolina: A 287(g) program focus. Sociology of Race and Ethnicity 3(3), 417-431.

Beckett, K., \& Evans, H. (2015). Crimmigration at the local level: Criminal justice processes in the shadow of deportation. Law. Soc. Rev. 49(1), 241-277.

Beckett, K., \& Western, B. (2001). Governing social marginality welfare, incarceration, and the transformation of state policy. Punishm. Soc. 3(1), 43-59.

Benin, M., \& Keith, V. M. (1995). The social support of employed African American and Anglo mothers. J. Family Issues 16(3), 275-297.

Bearman, P. S., \& Parigi, P. (2004). Cloning headless frogs and other important matters: Conversation topics and network structure. Soc. Forces 83(2), 535-557.

Besemer, K. L., van de Weijer, S. G., \& Dennison, S. M. (2018). The effect of family, household, and parental imprisonment on children and adults' social support and mental health. Crim. Just. Behav. 45(8), 1154-1173.

Billings, S. B. (2019). Parental arrest, incarceration and the outcomes of their children. SSRN Working Paper. URL: https://papers.ssrn.com/sol3/papers.cfm?abstract_id=3034539 (updated January 26, 2019).

Bott, E. (1957). Family and social network: Roles, norms, and external relationships in ordinary urban families. London: Tavistock Publications.

Braman, D. (2004). Doing time on the outside. Ann Arbor, MI: University of Michigan Press. 
Brashears, M. E. (2014). "Trivial" topics and rich ties: The relationship between discussion topics, alter role, and resource availability using the "important matters" name generator. Sociol. Sci. 1:493-511.

Brody, G. H. (1998). Sibling relationship quality: Its causes and consequences. Annu. Rev. Psych. 49:1-24.

Bruns, A. (2020). Partner incarceration and financial support from kin. J. Fam. Issues 41(11), 2112-2135.

Burt, R. S. (1984). Network items and the general social survey. Soc. Networks 6:293-339.

Christian, J. (2005). Riding the bus. J. Contemp. Crim. Just. 21(1), 31-48.

Cho, R. M. (2009). The impact of maternal imprisonment on children's educational achievement: Results from children in Chicago Public Schools. J. Hum Res. 44(3), 772-797.

Chung, P. H., \& Hepburn, P. 2018. Mass imprisonment and the extended family. Sociol. Sci. 5:335-360.

Clear, T. R. (2007). Imprisoning communities: How mass incarceration makes disadvantaged communities worse. New York: Oxford University Press.

Comfort, M. (2008). Doing time together: Love and family in the shadow of the prison. Chicago: University of Chicago Press.

Connidis, I. A., \& Campbell, L. D. (1995). Closeness, confiding, and contact among siblings in middle and late adulthood. J. Fam. Issues. 16(6), 722-745.

Coontz, Stephanie. 1992. The way we never were: American families and the nostalgia trap. New York: Basic Books.

Cross, C. J. (2018). Extended family households among children in the United States: Differences by race/ethnicity and socio-economic status. Popul. Stud. 72(2), 235-251.

Cross, C. J. (2020). Racial/ethnic differences in the association between family structure and children's education. J. Marriage Fam. 82(2), 691-712.

Daly, K. (1989). Rethinking judicial paternalism: Gender, work-family relations, and sentencing. Gend. 3(1), 9-36.

Dennis, J.M. (2016). Technical overview of the AmeriSpeak Panel: NORC's probability-based research panel. Chicago: NORC at the University of Chicago.

Dobbie, W., Grönqvist, H., Niknam, S., Palme, M., \& Priks, M. (2018). The intergenerational effects of parental incarceration. NBER Working Paper No. w24186. 
Eason, J. M. (2017). Big house on the prairie: Rise of the rural ghetto and prison proliferation. Chicago: University of Chicago Press.

Ebaugh, H. R., \& Curry, M. (2000). Fictive kin as social capital in new immigrant communities. Sociol. Persp. 43(2), 189-209.

Enns, P. K., Wildeman, C., Yi, Y., Comfort, M., Fitzpatrick, M., Goldman, A., Lee, H., Muller, C., Wakefield, S., and Wang, E. A., funded by FWD.us. (2018). Family History of Incarceration Study (FamHIS)—Release 1, Aug. 2018 [data set]. 31115615, Version 3, NORC at the University of Chicago [producer].

Enns, P. K., Yi, Y., Comfort, M., Goldman, A. W., Lee, H., Muller, C., Wakefield, S., Wang, E. A., Wildeman, C. (2019). What percentage of Americans have ever had a family member incarcerated?: Evidence from the Family History of Incarceration Survey (FamHIS). Socius 5:145 .

Eriksen, S., \& Gerstel, N. (2002). A labor of love or labor itself: Care work among adult brothers and sisters. J. Fam. Issues 23(7), 836-856.

Faber, J. (2020). We built this: Consequences of New Deal Era intervention in America's racial geography. Am. Sociol. Rev. 85(5), 739-775.

Fomby, P., \& Cherlin, A. J. (2007). Family instability and child well-being. Am. Sociol. Rev. 72:181-204.

Foster, H., \& Hagan, J. (2007). Incarceration and intergenerational social exclusion. Soc. Prob. 54(4), 399-433.

Foster, H., \& Hagan, J. (2015). Punishment regimes and the multilevel effects of parental incarceration: Intergenerational, intersectional, and interinstitutional models of social inequality and systemic exclusion. Annu. Rev. Sociol. 41:135-158.

Franklin, T. W. (2013). Sentencing Native Americans in US federal courts: An examination of disparity. Justice Q. 30(2), 310-339.

Geller, A., Jaeger, K., \& Pace, G. T. (2016). Surveys, records, and the study of incarceration in families. Ann. Am. Acad. Pol. Soc. Sci. 665(1), 22-43.

Gerstel, N. 2011. Rethinking families and community: The color, class, and centrality of extended kin ties. Sociol. Forum 26(1), 1-20.

Gillborn, D., Warmington, P., \& Demack, S. (2018). QuantCrit: Education, policy, "big data" and principles for a critical race theory of statistics. Race Ethn. Educ. 21(2), 158-179. 
Glick, J. E., Bean, F. D., \& Van Hook, J. V. W. (1997). Immigration and changing patterns of extended family household structure in the United States: 1970-1990. J. Marriage Fam. 59(1), $177-191$.

Goldman, A. W. (2020). Linked lives in double jeopardy: Child incarceration and maternal health at midlife. J. Health Soc. Behav. 60(4), 398-415.

Gottlieb, A. (2016). Household incarceration in early adolescence and risk of premarital first birth. Child. Youth Serv. Rev. 61:126-134.

Green, K. M., Ensminger, M. E., Robertson, J. A., \& Juon, H. (2018). Impact of adult sons' incarceration on African American mothers' psychological distress. J. Marriage Fam. 68(2), 430-441.

Gurusami, S. (2019). Motherwork under the state: The maternal labor of formerly incarcerated Black women. Soc. Prob. 66:128-143.

Hagan, J., \& Foster, H. (2012). Children of the American prison generation: Student and school spillover effects of incarcerating mothers. Law Soc. Rev. 46(1), 37-69.

Hall, M., \& Crowder, K. (2011). Extended-family resources and racial inequality in the transition to homeownership. Soc. Sci. Res. 40(6), 1534-1546.

Hall, E. L., \& Simkus, A. A. (1975). Inequality in the types of sentences received by Native Americans and whites. Criminology 13(2), 199-222.

Harding, D. J., Morenoff, J. D., Nguyen, A. P., \& Bushway, S. D. (2017). Short- and long-term effects of imprisonment on future felony convictions and prison admissions. PNAS 114(42), 11103-11108.

Harris, K. M. (2009). The National Longitudinal Study of Adolescent to Adult Health (Add Health), Waves I \& II, 1994-1996; Wave III, 2001-2002; Wave IV, 2007-2009 [machinereadable data file and documentation]. Chapel Hill, NC: Carolina Population Center, University of North Carolina at Chapel Hill.

Haskins, A. R. (2014). Unintended consequences: Effects of paternal incarceration on child school readiness and later special education placement. Sociol. Sci. 1:141-158.

Haynie, D. L., Whichard, C., Kreager, D. A., Schaefer, D. R., \& Wakefield, S. (2018). Social networks and health in a prison unit. J. Health Soc. Behav. 59(3), 318-334.

Heflin, C. M., \& Pattillo, M. (2006). Poverty in the family: Race, siblings, and socioeconomic heterogeneity. Soc. Sci. Res. 35(4), 804-822.

Jaeger, M. M. (2012). The extended family and children's educational success. Am. Sociol. Rev. 77(6), 903-922. 
Kang-Brown, J., \& R. Subramanian. 2017. Out of sight: The growth of jails in rural America. New York: Vera Institute of Justice.

Lantigua-Williams, Juleyka. (2016). When a sibling goes to prison. November 16. The Atlantic. URL: https://www.theatlantic.com/politics/archive/2016/11/when-a-sibling-goes-toprison/507020/ (accessed April 3, 2021).

Lee, H., Wildeman, C., Wang, E. A., Matsuko, N., \& Jackson, J. S. (2014). A heavy burden: The cardiovascular health consequences of having a family member incarcerated. Amer. J. Pub. Health 104(3), 421-427.

Lee, H., McCormick, T., Hicken, M. T., \& Wildeman, C. (2015). Racial inequalities in connectedness to imprisoned individuals in the United States. Du Bois Rev. 12(2), 269-282.

Lerman, A. E., \& Weaver, V. M. (2014). Staying out of sight? Concentrated policing and local political action. Ann. Am. Acad.. Pol. Soc. Sci. 651:202-219.

Madley, B. (2019). California's mass incarceration system: Franciscan missions, California Indians, and penal servitude, 1769-1836. Pac. Hist. Rev. 88(1), 14-47.

Marsden, P. V. (1987). Core discussion networks of Americans. Am. Sociol. Rev. 52(1), 122-131.

Massoglia, M., \& Pridemore, W. A. (2015). Incarceration and health. Annu. Rev. Sociol. 41:291310.

Meek, R. (2008). Experiences of younger siblings of young men in prison. Child. Soc. 22:265277.

Meissner, D., Kerwin, D. M., Chishti, M., \& Bergeron, C. (2013). Immigration enforcement in the United States: The rise of a formidable machinery. Washington, DC: Migration Policy Institute.

Menjívar, C., Cervantes, A. G., \& Alvord, D. (2018). The expansion of “crimmigration,” mass detention, and deportation. Sociol. Compass 12:e12573.

Miller, R. J. (2013). Race, hyper-incarceration, and US poverty policy in historic perspective. Sociol. Compass 7:573-589.

Moore, G. (1990). Structural determinants of men's and women's personal networks. Am. Sociol. Rev. 55(5), 726-735.

Mower, T. J., \& Visher, C. A. (2016). Changing the ties that bind: How incarceration impacts family relationships. Criminol. Pub. Pol. 15(2), 503-528.

Muller, C. (2012). Northward migration and the rise of racial disparity in American incarceration, 1880-1950. Am. J. Sociol. 2:281-326. 
Muller, C., \& Wildeman, C. 2016. Geographic variation in the cumulative risk of imprisonment and parental imprisonment in the United States. Demography 53:1499-1509.

Nelson, M. K. (2014). Whither fictive kin? Or, what's in a name? J. Fam. Issues 35(2), 201-222. NORC at the University of Chicago (NORC). (2019). "Panel Design - AmeriSpeak." Chicago: NORC at the University of Chicago.

Norris, S., Pecenco, M., \& Weaver, J. (2021). The effects of parental and sibling incarceration: Evidence from Ohio. SSRN Working Paper. URL:

https://papers.ssrn.com/sol3/papers.cfm?abstract_id=3590735 (updated March 2, 2021).

Nurse, A. M. (2002). Fatherhood arrested: Parenting from within the juvenile justice system. Nashville, TN: Vanderbilt University Press.

Patillo, M. E., Western, B., \& Weiman, D. (2004). Imprisoning America: The social effects of mass incarceration. New York: Russell Sage Foundation.

Perkins, K. L. (2017). Household complexity and change among children in the United States, 1984 to 2010. Sociol. Sci. 4:701-724.

Pettit, B. (2012). Invisible men: Mass incarceration and the myth of Black progress. New York: Russell Sage Foundation.

Pettit, B., \& Western, B. (2004). Mass imprisonment and the life course: Race and class inequality in U.S. incarceration. Am. Sociol. Rev. 69:151-169.

Pickett, J.T. (2016). On the social foundations for crimmigration: Latino threat and support for expanded police powers. 32:103-132.

Pilkauskas, N. V., \& Cross, C. (2018). Beyond the nuclear family: Trends in children living in shared households. Demography 55(6), 2283-2297.

Pridemore, W. A. (2014). The mortality penalty of incarceration: Evidence from a populationbased case-control study of working-age males. J. Health Soc. Behav. 55(2), 214-233.

Ray, V. (2019). A theory of racialized organized. Am. Sociol. Rev. 84(1), 26-53.

Roberts, D. E. (2002). Shattered bonds: The color of child welfare. New York: Basic Civitas Books.

Roberts, D. E. (2004). The social and moral cost of mass incarceration in African American communities. Stanford Law Review 56(5), 1271-1305.

Sarkisian, N. (2007). Street men, family men: Race and men's extended family involvement. Soc. Forces 86(2), 763-794. 
Sarkisian, N., Gerena, M., \& Gerstel, N. (2007). Extended family integration among Euro and Mexican Americans: Ethnicity, gender, and class. J. Marriage Fam. 69(1), 40-54.

Sarkisian, N., \& Gerstel, N. (2012). Nuclear family values, extended family lives. New York: Routledge.

Sewell, Abigail A. (2016). The racism-race reification process: A mesolevel political economic framework for understanding racial health disparities. Sociology of Race and Ethnicity 2(4), 402432.

Sirois, C. (2020). The strain of sons' incarceration in mothers' health. Soc. Sci. Med. 264(2), 113264.

Stack, C. B. (1974). All our kin: Strategies for survival in a Black community. New York: Harper \& Row.

Stewart, Q. T. (2008). Swimming upstream: Theory and methodology in race research. Chapter 6 in White Logic, White Methods: Racism and Methodology, Eds. T. Zuberi \& E. Bonilla-Silva. Lanham, MD: Rowman \& Littlefield Publishers, Inc.

Sundaresh, R., Yi, Y., Roy, B., Riley, C., Wildeman, C., \& Wang, E. A. (2020). Exposure to the US criminal legal system and well-being: A 2018 cross-sectional study. Am J. Pub. Health 110:S116-S122.

Swartz, T. T. (2009). Intergenerational family relations in adulthood: Patterns, variations, and implications in the contemporary United States. Annu. Rev. Sociol. 35:191-212.

Sykes, B. L., \& Pettit, B. (2014). Mass incarceration, family complexity, and the reproduction of childhood disadvantage. Ann. Am. Pol. Soc. Sci. 654:127-149.

Tach, L., \& Cornwell, B. (2015). Social networks and social capital: New directions for a household panel survey. J. Econ. Soc. Meas. 40(1-4), 249-291.

Thompson, H. A. (2020). The racial history of criminal justice in America. Du Bois Rev. 16(1), 221-241.

National Research Council. (2014). The growth of incarceration in the United States: Exploring causes and consequences, Eds. J. Travis, B. Western, \& S. Redburn. Washington, DC: The National Academies Press.

Turney, K. (2014). The intergenerational consequences of mass incarceration: Implications for children's co-residence and contact with grandparents. Soc. Forces 93(1), 299-327.

Turney, K. (2015). Hopelessly devoted? Relationship quality during and after incarceration. $J$. Marriage Fam. 77:480-495. 
Walmsley, R. (2018). World prison population list. $12^{\text {th }}$ edition. London: Institute for Criminal Policy Research.

Wakefield, S. (2016). Changing the ties that bind: Distinguishing the connected from the disconnected and accounting for the burdensome. Criminol. Pub. Pol. 15(2):543-549.

Wakefield, S., \& Uggen, C. (2010). Incarceration and stratification. Annu. Rev. Sociol. 36:387406.

Wakefield, S., \& Wildeman, C. (2014). Children of the prison boom: Mass incarceration and the future of American inequality. New York: Oxford University Press.

Waller, M. R., \& Swisher, R. (2006). Fathers' risk factors in fragile families: Implications for "healthy" relationships and father involvement. Soc. Prob. 53(3), 392-420.

Wasserman, S., \& Faust, K. (2009). Social network analysis: Methods and applications. Cambridge: Cambridge University Press.

Wellman, B., \& Wortley, S. (1990). Different strokes from different folks: Community ties and social support. Am. J. Sociol. 96(3):558-588.

Western, B. (2006). Punishment and inequality in America. New York: Russell Sage Foundation.

Western, B., \& Muller, C. (2013). Mass incarceration, macrosociology, and the poor. Ann. Am. Acad. Pol. Soc. Sci. 647:166-189.

White, L. K., \& Riedmann, A. (1992). Ties among adult siblings. Soc. Forces 71(1), 85-102.

Wildeman, C. (2009). Parental imprisonment, the prison boom, and the concentration of childhood disadvantage. Demography 46(2), 265-280.

Wildeman, C. (2012). Imprisonment and infant mortality. Soc. Prob. 59(2), 228-257.

Wildeman, C. (2020). The intergenerational transmission of criminal justice contact. Annu. Rev. Criminol. 3:2.1-2.28.

Wildeman, C., Goldman, A. W., \& Turney, K. (2018). Parental incarceration and child health in the United States. Epidemiol. Rev. 40:146-156.

Wildeman, C., \& Muller, C. (2012). Mass imprisonment and inequality in health and family life. Ann. Rev. Law. Soc. Sci. 8:11-30.

Wildeman, C., Turney, K., \& Yi, Y. (2016). Paternal incarceration and family functioning: Variation across federal, state, and local facilities. Ann. Acad. Pol. Soc. Sci. 665:80-97.

Wildeman, C., \& Wakefield, S. (2014). The long arm of the law: The concentration of incarceration in families in the era of mass incarceration. J. Gend. Race Soc. 17:367-389. 
Wildeman, C., \& Wang, E. A. (2017). Mass incarceration, public health, and widening inequality in the USA. Lancet 389:1464-1474.

Williams, D. R., \& Collins, C. 1995. US Socioeconomic and racial differences in health: Patterns and explanations. Annu. Rev. Sociol.21:349-386.

Wilson, W. J. (1987). The Truly disadvantaged: The inner city, the underclass, and public policy. Chicago: Univeresity of Chicago Press.

Youngblut, J. M., Brooten, D., Blais, K., Kilgore, C., \& Yoo, C. (2015). Health and functioning in grandparents after a young grandchild's death. J. Community Health 40:956-966. 


\section{TABLES AND FIGURES}

Table 1. Sample Description and Population Comparison

\begin{tabular}{|c|c|c|c|}
\hline & $\begin{array}{c}\text { FamHIS } \\
\text { Sample } \\
(\mathrm{N}=4,401)^{*}\end{array}$ & $\begin{array}{c}\text { Analytic } \\
\text { Sample } \\
(\mathrm{N}=\mathbf{2 , 0 2 9})\end{array}$ & $\begin{array}{c}\text { Population } \\
\text { Estimate }\end{array}$ \\
\hline \multicolumn{4}{|l|}{ Race/Ethnicity $(\%)^{\wedge}$} \\
\hline Black & 0.12 & 0.12 & 0.12 \\
\hline Hispanic & 0.16 & 0.17 & 0.15 \\
\hline White & 0.63 & 0.62 & 0.65 \\
\hline Other & 0.08 & 0.09 & 0.08 \\
\hline $\operatorname{Sex}(\% \text { Female })^{\wedge}$ & 0.52 & 0.52 & 0.51 \\
\hline \multirow[t]{2}{*}{ Age $(\text { Years })^{\wedge}$} & 47.40 & 47.71 & 46.99 \\
\hline & $(17.76)$ & $(17.73)$ & $(18.36)$ \\
\hline Born outside of U.S. $(\%)^{\wedge}$ & 0.14 & 0.14 & 0.17 \\
\hline Parental Status $(\%)+$ & 0.65 & 0.66 & 0.72 \\
\hline \multicolumn{4}{|l|}{ Partnership History/Status $(\%)^{\wedge}$} \\
\hline Currently Married & 0.47 & 0.47 & 0.50 \\
\hline Previously Married & 0.20 & 0.20 & 0.20 \\
\hline Living with Partner & 0.15 & 0.07 & na \\
\hline Never Married & 0.25 & 0.25 & 0.30 \\
\hline \multirow[t]{2}{*}{ Household Size (\#)+ } & 2.82 & 2.82 & 2.79 \\
\hline & $(1.51)$ & $(1.51)$ & $(1.47)$ \\
\hline \multicolumn{4}{|l|}{ Region $(\%)^{\wedge}$} \\
\hline Northeast & 0.17 & 0.17 & 0.18 \\
\hline Midwest & 0.21 & 0.21 & 0.21 \\
\hline South & 0.38 & 0.38 & 0.37 \\
\hline West & 0.25 & 0.24 & 0.23 \\
\hline Metropolitan Area $(\%)^{\wedge}$ & 0.88 & 0.88 & 0.42 \\
\hline \multicolumn{4}{|l|}{ Education^^${ }^{\wedge}$} \\
\hline No High School Diploma & 0.11 & 0.10 & 0.13 \\
\hline $\begin{array}{l}\text { High School Diploma, GED, } \\
\text { or Equivalent }\end{array}$ & 0.29 & 0.27 & 0.28 \\
\hline Some College & 0.28 & 0.28 & 0.31 \\
\hline Bachelor's Degree + & 0.33 & 0.35 & 0.28 \\
\hline \multicolumn{4}{|l|}{ Household Income $(\%)^{\wedge}$} \\
\hline$\$ 0-\$ 24,999$ & 0.23 & 0.21 & 0.21 \\
\hline$\$ 25,000-\$ 49,999$ & 0.26 & 0.27 & 0.22 \\
\hline$\$ 50,000-\$ 74,999$ & 0.17 & 0.17 & 0.18 \\
\hline$\$ 75,000$ - $\$ 99,999$ & 0.13 & 0.14 & 0.13 \\
\hline$\$ 100,000+$ & 0.20 & 0.21 & 0.27 \\
\hline
\end{tabular}

Notes: ^ Population estimates from the 2012-2016 American Community Survey. +Population estimates from the 2012-2016 General Social Survey (. Estimates are weighted to be representative of the non-institutionalized adult U.S. population. Standard deviations are denoted in parentheses. "Estimates for the full FamHIS sample draw on data from all 4,401 respondents for all measures except for U.S. nativity, for which there are data for only the 2,806 respondents who completed the full questionnaire (Enns et al. 2018). "na" indicates that estimates were not available. 
Table 2. Statistical Summary of Measures of Family Incarceration

\begin{tabular}{|c|c|c|c|c|c|}
\hline & \multirow[b]{2}{*}{$\begin{array}{c}\text { Overall } \\
(\mathbf{N}=\mathbf{2 , 0 2 9})\end{array}$} & \multicolumn{4}{|c|}{ Race/Ethnicity } \\
\hline & & $\begin{array}{c}\text { Black } \\
(\mathrm{N}=291)\end{array}$ & $\begin{array}{c}\text { Hispanic } \\
(\mathrm{N}=289)\end{array}$ & $\begin{array}{c}\text { White } \\
(\mathrm{N}=\mathbf{1 , 2 7 0})\end{array}$ & $\begin{array}{c}\text { Other } \\
(\mathrm{N}=179)\end{array}$ \\
\hline \multicolumn{6}{|l|}{ Prevalence/Risk (\%) } \\
\hline Immediate & 0.40 & 0.60 & 0.42 & 0.37 & 0.33 \\
\hline Extended & 0.34 & 0.53 & 0.36 & 0.31 & 0.31 \\
\hline Immediate or Extended & 0.52 & 0.74 & 0.52 & 0.49 & 0.44 \\
\hline \multicolumn{6}{|l|}{ Degree (\# Family Members) } \\
\hline Immediate & $\begin{array}{c}0.99 \\
(1.87)\end{array}$ & $\begin{array}{c}2.11 \\
(2.93)\end{array}$ & $\begin{array}{c}1.12 \\
(1.98)\end{array}$ & $\begin{array}{c}0.75 \\
(1.43)\end{array}$ & $\begin{array}{c}0.91 \\
(1.99)\end{array}$ \\
\hline Extended & $\begin{array}{c}1.53 \\
(3.06)\end{array}$ & $\begin{array}{c}3.20 \\
(4.38)\end{array}$ & $\begin{array}{c}1.68 \\
(3.15)\end{array}$ & $\begin{array}{c}1.17 \\
(2.54)\end{array}$ & $\begin{array}{c}1.53 \\
(3.30)\end{array}$ \\
\hline Immediate or Extended & $\begin{array}{c}2.52 \\
(4.32)\end{array}$ & $\begin{array}{c}5.30 \\
(6.26)\end{array}$ & $\begin{array}{c}2.80 \\
(4.37)\end{array}$ & $\begin{array}{c}1.92 \\
(3.47)\end{array}$ & $\begin{array}{c}2.44 \\
(4.86)\end{array}$ \\
\hline \multicolumn{6}{|l|}{ Extension (\%) } \\
\hline Horizontal & 0.44 & 0.66 & 0.49 & 0.39 & 0.39 \\
\hline Upward & 0.30 & 0.49 & 0.34 & 0.26 & 0.31 \\
\hline Downward & 0.19 & 0.34 & 0.14 & 0.18 & 0.13 \\
\hline Permeation (\# Generations) & $\begin{array}{c}1.06 \\
(1.26)\end{array}$ & $\begin{array}{c}1.72 \\
(1.42)\end{array}$ & $\begin{array}{c}1.10 \\
(1.26)\end{array}$ & $\begin{array}{c}0.93 \\
(1.18)\end{array}$ & $\begin{array}{c}0.95 \\
(1.28)\end{array}$ \\
\hline
\end{tabular}

Notes: Estimates are weighted to be representative of the non-institutionalized adult U.S. population. Standard deviations are noted in parentheses. 
Table 3. Associations between Family Incarceration Prevalence and Race/Ethnicity

\begin{tabular}{|c|c|c|c|c|}
\hline & \multicolumn{4}{|c|}{ Immediate Family } \\
\hline & (1) & $(2)$ & $(3)$ & (4) \\
\hline \multirow[t]{2}{*}{ Overall } & 0.40 & 0.40 & 0.40 & 0.40 \\
\hline & $(0.38,0.43)$ & $(0.38,0.43)$ & $(0.38,0.43)$ & $(0.38,0.43)$ \\
\hline \multicolumn{5}{|l|}{ By Race/Ethnicity } \\
\hline \multirow[t]{2}{*}{ Black } & $0.60^{\mathrm{H}, \mathrm{O}, \mathrm{W}}$ & $0.60^{\mathrm{H}, \mathrm{O}, \mathrm{W}}$ & $0.60^{\mathrm{H}, \mathrm{O}, \mathrm{W}}$ & $0.60^{\mathrm{H}, \mathrm{O}, \mathrm{W}}$ \\
\hline & $(0.52,0.69)$ & $(0.52,0.69)$ & $(0.51,0.69)$ & $(0.51,0.69)$ \\
\hline \multirow[t]{2}{*}{ Hispanic } & $0.42^{\mathrm{B}}$ & $0.42^{\mathrm{B}}$ & $0.42^{\mathrm{B}}$ & $0.42^{\mathrm{B}}$ \\
\hline & $(0.34,0.50)$ & $(0.34,0.50)$ & $(0.34,0.50)$ & $(0.34,0.50)$ \\
\hline \multirow[t]{2}{*}{ Other } & $0.33^{\mathrm{B}}$ & $0.33^{\mathrm{B}}$ & $0.33^{\mathrm{B}}$ & $0.33^{\mathrm{B}}$ \\
\hline & $(0.25,0.41)$ & $(0.26,0.40)$ & $(0.26,0.40)$ & $(0.26,0.40)$ \\
\hline \multirow[t]{4}{*}{ White } & $0.37^{\mathrm{B}}$ & $0.37^{\mathrm{B}}$ & $0.37^{\mathrm{B}}$ & $0.37^{\mathrm{B}}$ \\
\hline & $(0.34,0.40)$ & $(0.34,0.40)$ & $(0.34,0.40)$ & $(0.34,0.40)$ \\
\hline & \multicolumn{4}{|c|}{ Extended Family } \\
\hline & $(1)$ & $(2)$ & $(3)$ & (4) \\
\hline \multirow[t]{2}{*}{ Overall } & 0.35 & 0.34 & 0.34 & 0.34 \\
\hline & $(0.32,0.37)$ & $(0.32,0.37)$ & $(0.32,0.37)$ & $(0.32,0.37)$ \\
\hline \multicolumn{5}{|l|}{ By Race/Ethnicity } \\
\hline \multirow[t]{2}{*}{ Black } & $0.53^{\mathrm{H}, \mathrm{O}, \mathrm{W}}$ & $0.53^{\mathrm{H}, \mathrm{O}, \mathrm{W}}$ & $0.53^{\mathrm{H}, \mathrm{O}, \mathrm{W}}$ & $0.53^{\mathrm{H}, \mathrm{O}, \mathrm{W}}$ \\
\hline & $(0.45,0.61)$ & $(0.45,0.61)$ & $(0.44,0.61)$ & $(0.44,0.61)$ \\
\hline \multirow[t]{2}{*}{ Hispanic } & $0.36^{\mathrm{B}}$ & $0.36^{\mathrm{B}}$ & $0.36^{\mathrm{B}}$ & $0.36^{\mathrm{B}}$ \\
\hline & $(0.28,0.44)$ & $(0.28,0.44)$ & $(0.28,0.44)$ & $(0.28,0.44)$ \\
\hline \multirow[t]{2}{*}{ Other } & $0.31^{\mathrm{B}}$ & $0.31^{\mathrm{B}}$ & $0.31^{\mathrm{B}}$ & $0.31^{\mathrm{B}}$ \\
\hline & $(0.23,0.39)$ & $(0.24,0.39)$ & $(0.24,0.39)$ & $(0.24,0.39)$ \\
\hline \multirow[t]{4}{*}{ White } & $0.31^{\mathrm{B}}$ & $0.31^{\mathrm{B}}$ & $0.31^{\mathrm{B}}$ & $0.31^{\mathrm{B}}$ \\
\hline & $(0.27,0.34)$ & $(0.27,0.34)$ & $(0.28,0.34)$ & $(0.28,0.34)$ \\
\hline & \multicolumn{4}{|c|}{ Any Immediate or Extended Family } \\
\hline & $(1)$ & $(2)$ & (3) & $(4)$ \\
\hline \multirow[t]{2}{*}{ Overall } & 0.52 & 0.52 & 0.52 & 0.52 \\
\hline & $(0.49,0.55)$ & $(0.49,0.55)$ & $(0.49,0.55)$ & $(0.49,0.55)$ \\
\hline \multicolumn{5}{|l|}{ By Race/Ethnicity } \\
\hline \multirow[t]{2}{*}{ Black } & $0.74^{\mathrm{H}, \mathrm{O}, \mathrm{W}}$ & $0.74^{\mathrm{H}, \mathrm{O}, \mathrm{W}}$ & $0.74^{\mathrm{H}, \mathrm{O}, \mathrm{W}}$ & $0.74^{\mathrm{H}, \mathrm{O}, \mathrm{W}}$ \\
\hline & $(0.65,0.82)$ & $(0.65,0.82)$ & $(0.65,0.82)$ & $(0.65,0.82)$ \\
\hline \multirow[t]{2}{*}{ Hispanic } & $0.52^{\mathrm{B}}$ & $0.52^{\mathrm{B}}$ & $0.52^{\mathrm{B}}$ & $0.52^{\mathrm{B}}$ \\
\hline & $(0.43,0.61)$ & $(0.43,0.61)$ & $(0.43,0.61)$ & $(0.43,0.61)$ \\
\hline \multirow[t]{2}{*}{ Other } & $0.44^{\mathrm{B}}$ & $0.44^{\mathrm{B}}$ & $0.44^{\mathrm{B}}$ & $0.44^{\mathrm{B}}$ \\
\hline & $(0.34,0.53)$ & $(0.36,0.52)$ & $(0.36,0.52)$ & $(0.36,0.52)$ \\
\hline \multirow[t]{2}{*}{ White } & $0.49^{\mathrm{B}}$ & $0.49^{\mathrm{B}}$ & $0.49^{\mathrm{B}}$ & $0.49^{\mathrm{B}}$ \\
\hline & $(0.45,0.52)$ & $(0.45,0.52)$ & $(0.45,0.52)$ & $(0.45,0.52)$ \\
\hline Race/Ethnicity & $\mathrm{X}$ & $\mathrm{X}$ & $\mathrm{X}$ & $\mathrm{X}$ \\
\hline Life Course Characteristics & & $X$ & $X$ & $X$ \\
\hline Spatial Characteristics & & & $\mathrm{X}$ & $X$ \\
\hline Socioeconomic Characteristics & & & & $\mathrm{X}$ \\
\hline
\end{tabular}

Notes: $\mathrm{N}=2,029$. Estimates are presented as predicted probabilities from weighted logistic regression models. $95 \%$ confidence intervals are reported in parentheses. Superscript letters denote estimates that are statistically distinguishable from respondents who identified as ${ }^{\mathrm{B}} \mathrm{B}$ lack, ${ }^{\mathrm{H}}$ Hispanic, ${ }^{\mathrm{O}}$ Other, and ${ }^{\mathrm{W}}$ White race/ethnicity at the 95 -percent confidence level. 
Fig. 1. Estimated Associations between Prevalence of Family Incarceration and Race/Ethnicity, by Family Member Type
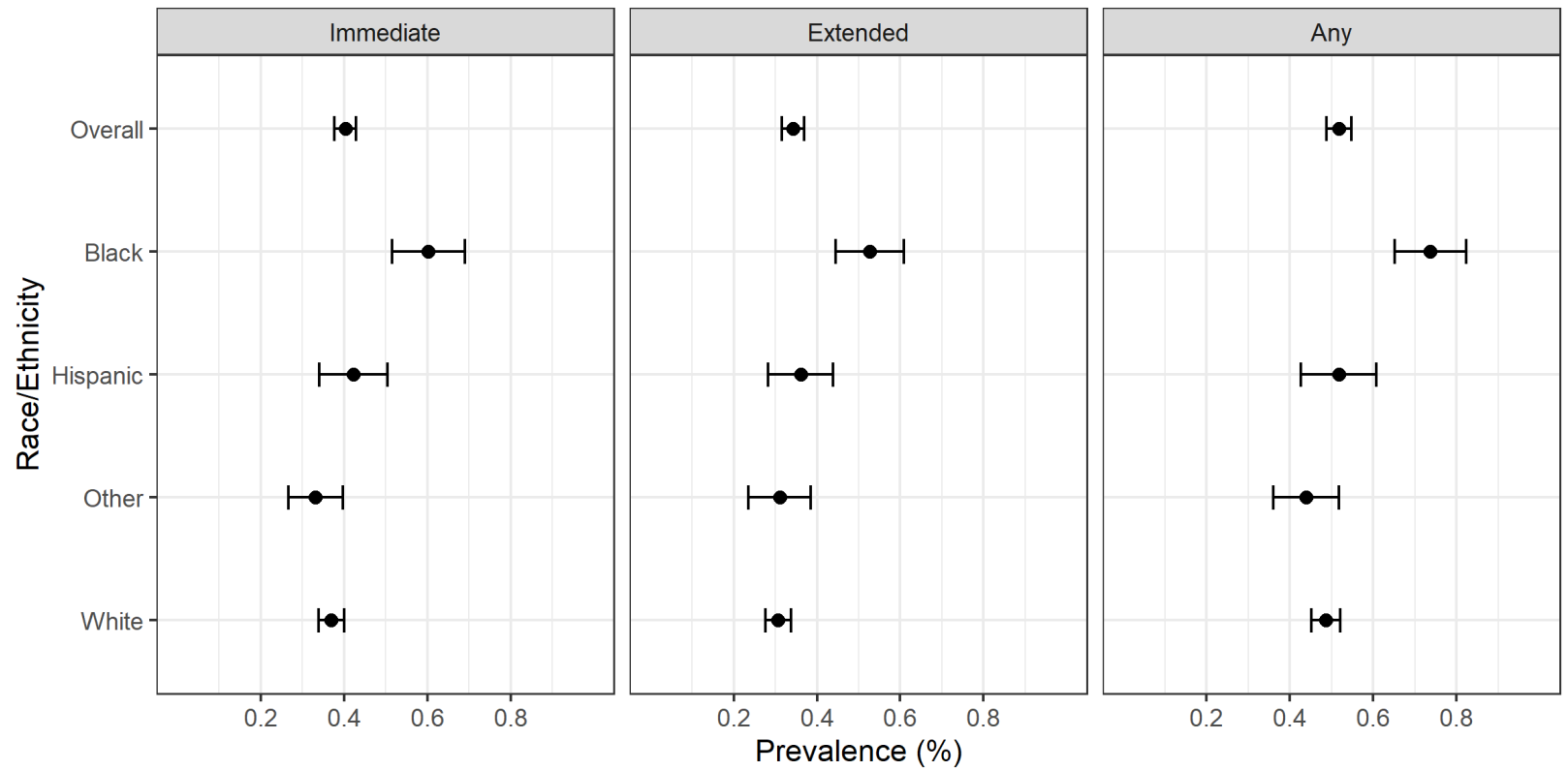

Notes: $\mathrm{N}=2,029$. Dots report predicted probabilities of likelihood of experiencing each type of family member incarceration. Whiskers report $95 \%$ confidence intervals. Results presented here are from the fully adjusted weighted regression model (Model 4), which include covariates for race/ethnicity, life course characteristics, spatial characteristics, and socioeconomic characteristics of the respondent. 
Fig. 2. Estimated Associations between Degree of Family Incarceration and Race/Ethnicity, by Family Member Type
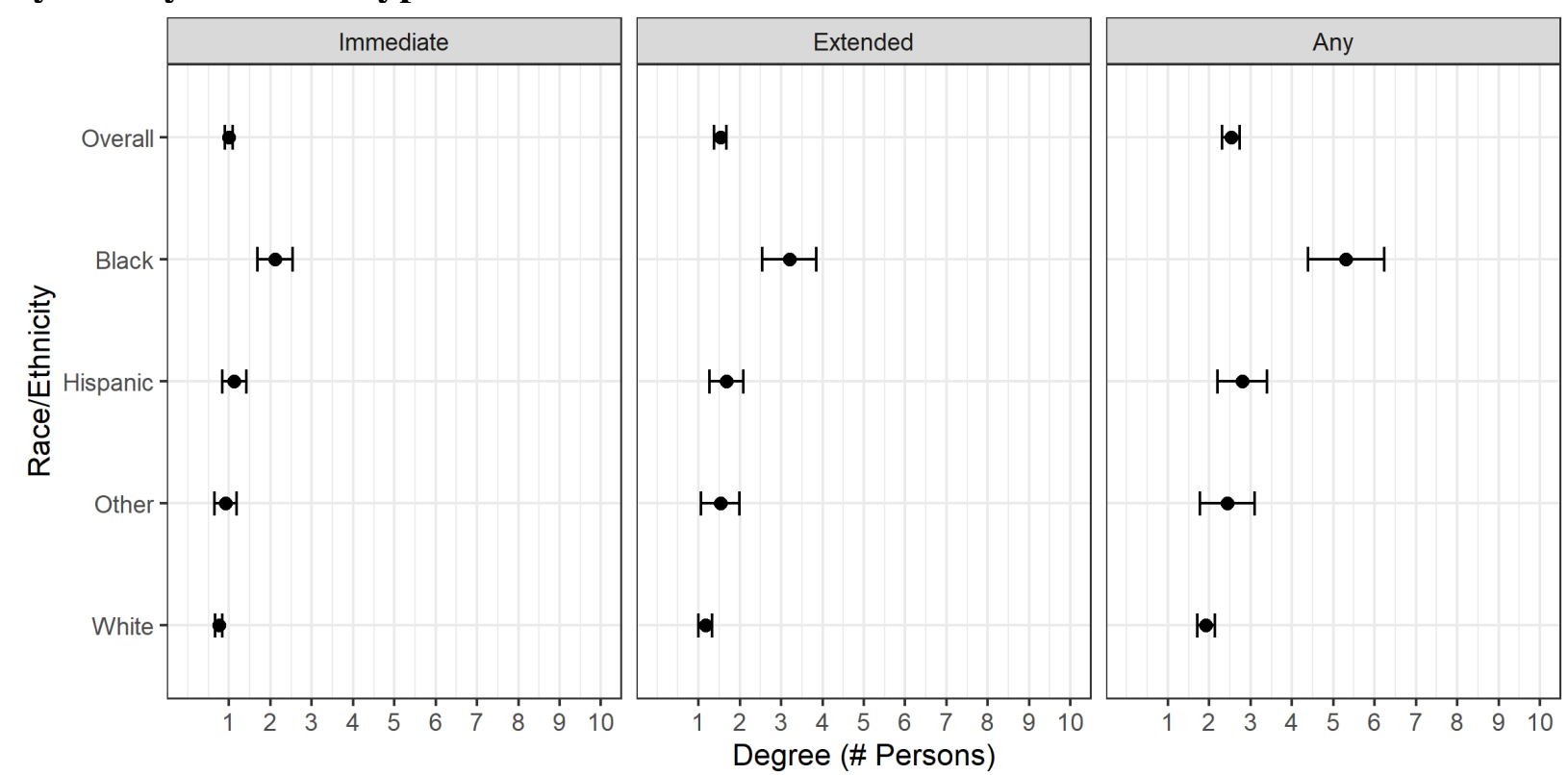

Notes: $N=2,029$. Dots report predicted degree of family incarceration, reported as a number of family members ever incarcerated. Whiskers report $95 \%$ confidence intervals. Results presented here are from the fully adjusted weighted regression model (Model 4), which include covariates for race/ethnicity, life course characteristics, spatial characteristics, and socioeconomic characteristics of the respondent. 
Fig. 3. Estimated Associations between Generational Extension of Family Incarceration and Race/Ethnicity, by Direction
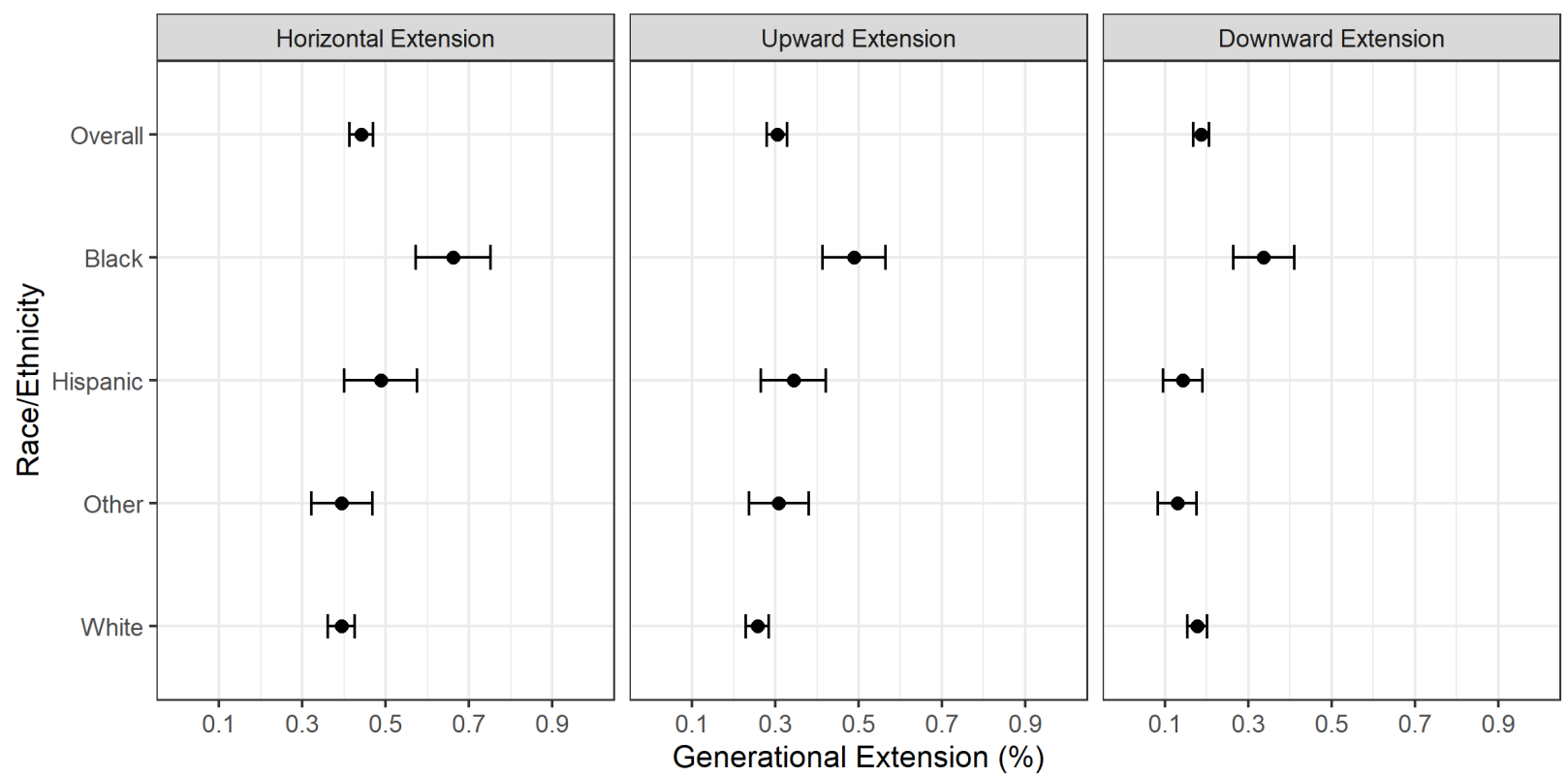

Notes: $N=2,029$. Dots report predicted probability of experiencing family incarceration by each type of generational extension. Whiskers report 95\% confidence intervals. Results presented here are from the fully adjusted weighted regression model (Model 4), which include covariates for race/ethnicity, life course characteristics, spatial characteristics, and socioeconomic characteristics of the respondent. 
Fig. 4. Estimated Associations between Permeation of Family Incarceration and Race/Ethnicity

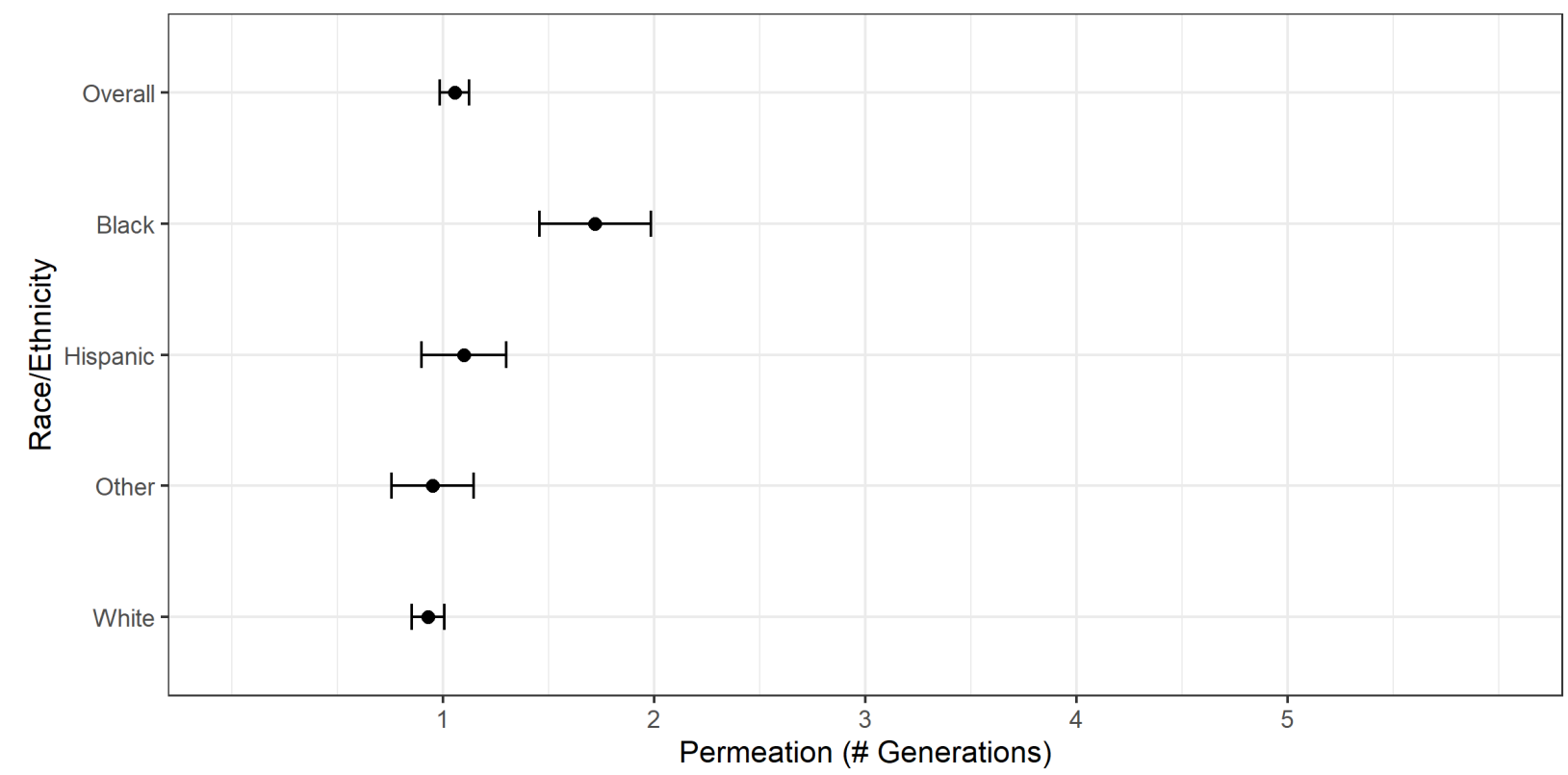

Notes: $\mathrm{N}=2,029$. Dots report predicted permeation of family incarceration, reported as a number of generations with family incarceration. Whiskers report $95 \%$ confidence intervals. Results presented here are from the fully adjusted weighted regression model (Model 4), which include covariates for race/ethnicity, life course characteristics, spatial characteristics, and socioeconomic characteristics of the respondent. 
Table 1. Sample Description and Population Comparison

\begin{tabular}{|c|c|c|c|}
\hline & $\begin{array}{c}\text { FamHIS } \\
\text { Sample } \\
(\mathbf{N}=\mathbf{4 , 4 0 1})^{*}\end{array}$ & $\begin{array}{c}\text { Analytic } \\
\text { Sample } \\
(\mathbf{N}=\mathbf{2 , 0 2 9})\end{array}$ & $\begin{array}{c}\text { Multiply Imputed } \\
\text { Sample } \\
(\mathbf{N}=\mathbf{2 , 8 1 5})\end{array}$ \\
\hline \multicolumn{4}{|l|}{ Race/Ethnicity $(\%)^{\wedge}$} \\
\hline Black & 0.12 & 0.12 & 0.12 \\
\hline Hispanic & 0.16 & 0.17 & 0.16 \\
\hline White & 0.63 & 0.62 & 0.63 \\
\hline Other & 0.08 & 0.09 & 0.09 \\
\hline Sex $(\% \text { Female })^{\wedge}$ & 0.52 & 0.52 & 0.52 \\
\hline \multirow{2}{*}{ Age (Years)^ } & 47.40 & 47.71 & 47.70 \\
\hline & (17.76) & (17.73) & (17.76) \\
\hline Born outside of U.S. $(\%)^{\wedge}$ & 0.14 & 0.14 & 0.14 \\
\hline Parental Status $(\%)+$ & 0.65 & 0.66 & 0.67 \\
\hline \multicolumn{4}{|l|}{ Partnership History/Status $(\%)^{\wedge}$} \\
\hline Currently Married & 0.47 & 0.47 & 0.47 \\
\hline Previously Married & 0.20 & 0.20 & 0.21 \\
\hline Living with Partner & 0.15 & 0.07 & 0.08 \\
\hline Never Married & 0.25 & 0.25 & 0.24 \\
\hline \multirow[t]{2}{*}{ Household Size (\#)+ } & 2.82 & 2.82 & 2.82 \\
\hline & $(1.51)$ & $(1.51)$ & $(1.51)$ \\
\hline \multicolumn{4}{|l|}{ Region $(\%)^{\wedge}$} \\
\hline Northeast & 0.17 & 0.17 & 0.17 \\
\hline Midwest & 0.21 & 0.21 & 0.21 \\
\hline South & 0.38 & 0.38 & 0.38 \\
\hline West & 0.25 & 0.24 & 0.25 \\
\hline Metropolitan Area (\%)^ & 0.88 & 0.88 & 0.88 \\
\hline \multicolumn{4}{|l|}{ Education^^} \\
\hline No High School Diploma & 0.11 & 0.10 & 0.11 \\
\hline $\begin{array}{l}\text { High School Diploma, GED, } \\
\text { or Equivalent }\end{array}$ & 0.29 & 0.27 & 0.29 \\
\hline Some College & 0.28 & 0.28 & 0.28 \\
\hline Bachelor's Degree + & 0.33 & 0.35 & 0.33 \\
\hline \multicolumn{4}{|l|}{ Household Income $(\%)^{\wedge}$} \\
\hline$\$ 0-\$ 24,999$ & 0.23 & 0.21 & 0.23 \\
\hline$\$ 25,000-\$ 49,999$ & 0.26 & 0.27 & 0.26 \\
\hline$\$ 50,000-\$ 74,999$ & 0.17 & 0.17 & 0.17 \\
\hline$\$ 75,000-\$ 99,999$ & 0.13 & 0.14 & 0.13 \\
\hline$\$ 100,000+$ & 0.20 & 0.21 & 0.20 \\
\hline
\end{tabular}

Notes: Estimates are weighted to be representative of the non-institutionalized adult U.S. population. Standard deviations are denoted in parentheses. "Estimates for the full FamHIS sample draw on data from all 4,401 respondents for all measures except for U.S. nativity, which was only asked of the 2,806 respondents who were sampled into the full FamHIS questionnaire (Enns et al. 2018). 
Table 2. Associations between Degree of Family Incarceration and Race/Ethnicity

\begin{tabular}{|c|c|c|c|c|}
\hline & \multicolumn{4}{|c|}{ Immediate Family } \\
\hline & $(1)$ & $(2)$ & (3) & $(4)$ \\
\hline \multirow[t]{2}{*}{ Overall } & 0.99 & 0.99 & 0.99 & 0.99 \\
\hline & $(0.90,1.09)$ & $(0.90,1.09)$ & $(0.90,1.09)$ & $(0.90,1.09)$ \\
\hline \multicolumn{5}{|l|}{ By Race/Ethnicity } \\
\hline \multirow[t]{2}{*}{ Black } & $2.11^{\mathrm{W}, \mathrm{H}, \mathrm{O}}$ & $2.11^{\mathrm{W}, \mathrm{H}, \mathrm{O}}$ & $2.11^{\mathrm{W}, \mathrm{H}, \mathrm{O}}$ & $2.11^{\mathrm{W}, \mathrm{H}, \mathrm{O}}$ \\
\hline & $(1.68,2.54)$ & $(1.68,2.53)$ & $(1.68,2.53)$ & $(1.68,2.53)$ \\
\hline \multirow[t]{2}{*}{ Hispanic } & $1.12^{\mathrm{B}}$ & $1.12^{\mathrm{B}}$ & $1.12^{\mathrm{B}}$ & $1.12^{\mathrm{B}}$ \\
\hline & $(0.82,1.43)$ & $(0.84,1.40)$ & $(0.84,1.40)$ & $(0.83,1.42)$ \\
\hline \multirow[t]{2}{*}{ Other } & $0.91^{\mathrm{B}}$ & $0.91^{\mathrm{B}}$ & $0.91^{\mathrm{B}}$ & $0.91^{\mathrm{B}}$ \\
\hline & $(0.61,1.22)$ & $(0.63,1.19)$ & $(0.63,1.19)$ & $(0.64,1.18)$ \\
\hline \multirow[t]{4}{*}{ White } & $0.75^{\mathrm{B}}$ & $0.75^{\mathrm{B}}$ & $0.75^{\mathrm{B}}$ & $0.75^{\mathrm{B}}$ \\
\hline & $(0.67,0.84)$ & $(0.66,0.84)$ & $(0.66,0.84)$ & $(0.67,0.84)$ \\
\hline & \multicolumn{4}{|c|}{ Extended Family } \\
\hline & $(1)$ & (2) & (3) & (4) \\
\hline \multirow[t]{2}{*}{ Overall } & 1.53 & 1.53 & 1.53 & 1.53 \\
\hline & $(1.37,1.69)$ & $(1.37,1.69)$ & $(1.37,1.68)$ & (1.378 1.68) \\
\hline \multicolumn{5}{|l|}{ By Race/Ethnicity } \\
\hline \multirow[t]{2}{*}{ Black } & $3.20^{\mathrm{W}, \mathrm{H}, \mathrm{O}}$ & $3.20^{\mathrm{W}, \mathrm{H}, \mathrm{O}}$ & $3.20^{\mathrm{W}, \mathrm{H}, \mathrm{O}}$ & $3.20^{\mathrm{W}, \mathrm{H}, \mathrm{O}}$ \\
\hline & $(2.54,3.86)$ & $(2.54,3.86)$ & $(2.54,3.86)$ & $(2.55,3.85)$ \\
\hline \multirow[t]{2}{*}{ Hispanic } & $1.68^{\mathrm{B}}$ & $1.68^{\mathrm{B}}$ & $1.68^{\mathrm{B}}$ & $1.68^{\mathrm{B}}$ \\
\hline & $(1.26,2.09)$ & $(1.26,2.10)$ & $(1.26,2.09)$ & $(1.26,2.09)$ \\
\hline \multirow[t]{2}{*}{ Other } & $1.53^{\mathrm{B}}$ & $1.53^{\mathrm{B}}$ & $1.53^{\mathrm{B}}$ & $1.53^{\mathrm{B}}$ \\
\hline & $(0.99,2.07)$ & $(1.03,2.02)$ & $(1.04,2.01)$ & $(1.05,2.00)$ \\
\hline \multirow[t]{4}{*}{ White } & $1.17^{\mathrm{B}}$ & $1.17^{\mathrm{B}}$ & $1.17^{\mathrm{B}}$ & $1.17^{\mathrm{B}}$ \\
\hline & $(1.00,1.34)$ & $(1.00,1.34)$ & $(1.00,1.34)$ & $(1.00,1.33)$ \\
\hline & \multicolumn{4}{|c|}{ Any Immediate or Extended Family } \\
\hline & (1) & $(2)$ & $(3)$ & (4) \\
\hline \multirow[t]{2}{*}{ Overall } & 2.52 & 2.52 & 2.52 & 2.52 \\
\hline & $(2.30,2.74)$ & $(2.31,2.74)$ & $(2.31,2.74)$ & $(2.31,2.73)$ \\
\hline \multicolumn{5}{|l|}{ By Race/Ethnicity } \\
\hline \multirow[t]{2}{*}{ Black } & $5.30^{\mathrm{W}, \mathrm{H}, \mathrm{O}}$ & $5.30^{\mathrm{W}, \mathrm{H}, \mathrm{O}}$ & $5.30^{\mathrm{W}, \mathrm{H}, \mathrm{O}}$ & $5.30^{\mathrm{W}, \mathrm{H}, \mathrm{O}}$ \\
\hline & $(4.38,6.23)$ & $(4.38,6.23)$ & $(4.37,6.24)$ & $(4.38,6.23)$ \\
\hline \multirow[t]{2}{*}{ Hispanic } & $2.80^{\mathrm{B}, \mathrm{W}}$ & $2.80^{\mathrm{B}, \mathrm{W}}$ & $2.80^{\mathrm{B}, \mathrm{W}}$ & $2.80^{\mathrm{B}, \mathrm{W}}$ \\
\hline & $(2.19,3.40)$ & $(2.21,3.39)$ & $(2.22,3.37)$ & $(2.20,3.40)$ \\
\hline \multirow[t]{2}{*}{ Other } & $2.44^{\mathrm{B}}$ & $2.44^{\mathrm{B}}$ & $2.44^{\mathrm{B}}$ & $2.44^{\mathrm{B}}$ \\
\hline & $(1.66 .3 .21)$ & $(1.75 .3 .12)$ & $(1.76 .3 .12)$ & $(1.78 .3 .09)$ \\
\hline \multirow[t]{2}{*}{ White } & $1.92^{\mathrm{B}, \mathrm{H}}$ & $1.92^{\mathrm{B}, \mathrm{H}}$ & $1.92^{\mathrm{B}, \mathrm{H}}$ & $1.92^{\mathrm{B}, \mathrm{H}}$ \\
\hline & $(1.69,2.15)$ & $(1.69,2.15)$ & $(1.70,2.15)$ & $(1.70,2.14)$ \\
\hline Race/Ethnicity & $\mathrm{X}$ & $\mathrm{X}$ & $\mathrm{X}$ & $\mathrm{X}$ \\
\hline Life Course Characteristics & & $X$ & $X$ & $X$ \\
\hline Spatial Characteristics & & & $X$ & $X$ \\
\hline Socioeconomic Characteristics & & & & $\mathrm{X}$ \\
\hline
\end{tabular}

Notes: $\mathrm{N}=2,029$. Estimates are presented as linear predictions from weighted ordinary least squares regression models. 95\% confidence intervals are reported in parentheses. Superscript letters denote estimates that are statistically distinguishable from respondents who identified as ${ }^{\mathrm{B}}$ Black, ${ }^{\mathrm{H}}$ Hispanic, ${ }^{\mathrm{O}}$ Other, and ${ }^{\mathrm{W}}$ White race/ethnicity at the 95 -percent confidence level. 
Table 3. Associations between Generational Extension of Family Incarceration and Race/Ethnicity

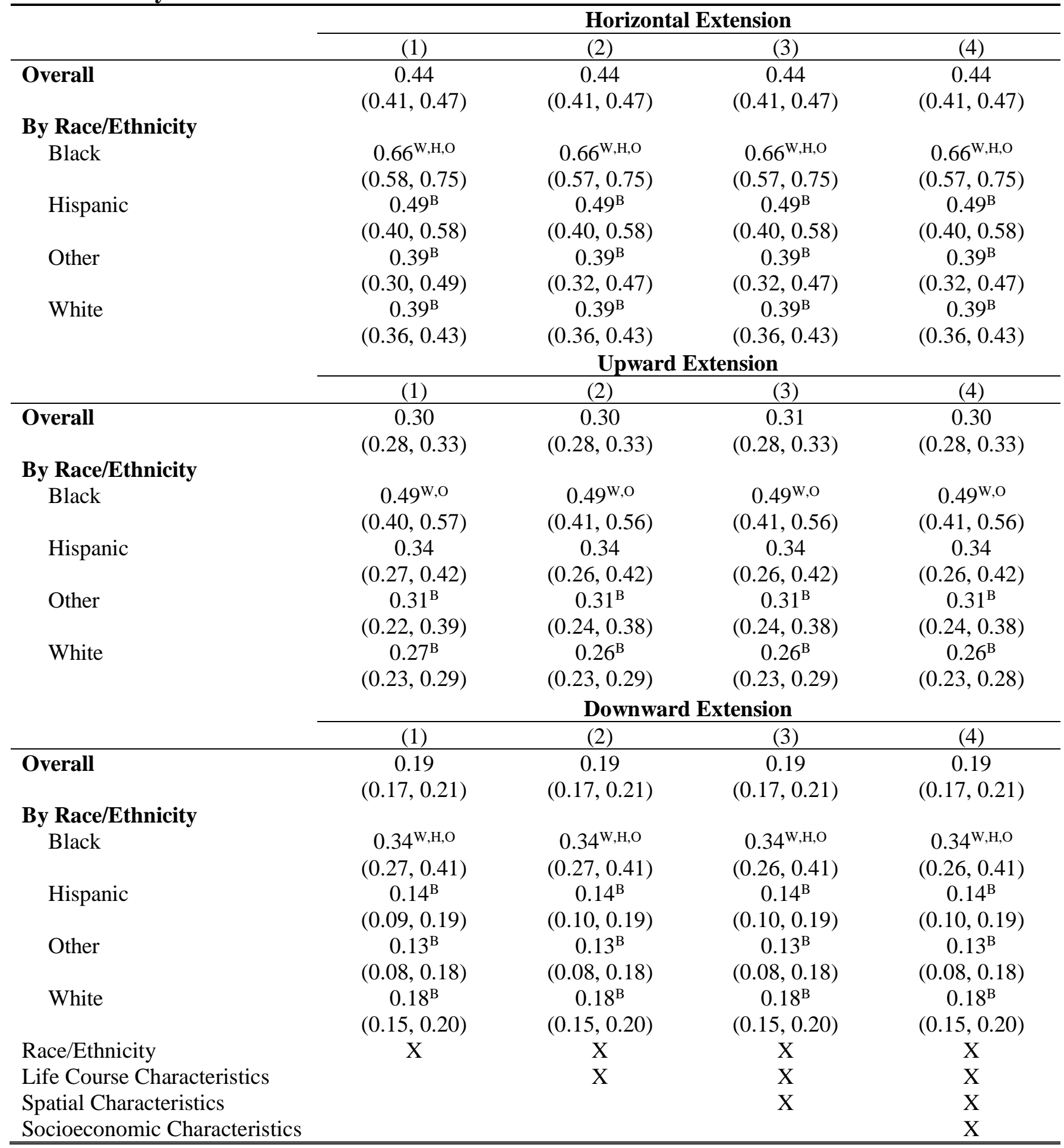

Notes: $\mathrm{N}=2,029$. Estimates are presented as predicted probabilities from weighted logistic logistic regression models. 95\% confidence intervals are reported in parentheses. Superscript letters denote estimates that are statistically distinguishable from respondents who identified as ${ }^{\mathrm{B}}$ Black, ${ }^{\mathrm{H}}$ Hispanic, ${ }^{\mathrm{O}}$ Other, and ${ }^{\mathrm{W}}$ White race/ethnicity at the 95 -percent confidence level. 
Table 4. Associations between Family Incarceration Permeation and Race/Ethnicity

\begin{tabular}{|c|c|c|c|c|}
\hline & \multicolumn{4}{|c|}{ Number of Generations $(0-5)$} \\
\hline & $(1)$ & $(2)$ & (3) & $(4)$ \\
\hline \multirow[t]{2}{*}{ Overall } & 1.06 & 1.06 & 1.06 & 1.06 \\
\hline & $(0.98,1.13)$ & $(0.98,1.13)$ & $(0.99,1.13)$ & $(0.99,1.12)$ \\
\hline \multicolumn{5}{|l|}{ By Race/Ethnicity } \\
\hline \multirow[t]{2}{*}{ Black } & $1.72^{\mathrm{W}, \mathrm{H}, \mathrm{O}}$ & $1.72^{\mathrm{W}, \mathrm{H}, \mathrm{O}}$ & $1.72^{\mathrm{W}, \mathrm{H}, \mathrm{O}}$ & $1.72^{\mathrm{W}, \mathrm{H}, \mathrm{O}}$ \\
\hline & $(1.48,1.96)$ & $(1.47,1.97)$ & $(1.46,1.98)$ & $(1.46,1.98)$ \\
\hline \multirow[t]{2}{*}{ Hispanic } & $1.10^{\mathrm{B}}$ & $1.10^{\mathrm{B}}$ & $1.10^{\mathrm{B}}$ & $1.10^{\mathrm{B}}$ \\
\hline & $(0.90,1.30)$ & $(0.90,1.30)$ & $(0.90,1.30)$ & $(0.90,1.30)$ \\
\hline \multirow[t]{2}{*}{ Other } & $0.95^{\mathrm{B}}$ & $0.95^{\mathrm{B}}$ & $0.95^{\mathrm{B}}$ & $0.95^{\mathrm{B}}$ \\
\hline & $(0.71,1.19)$ & $(0.75,1.15)$ & $(0.76,1.15)$ & $(0.76,1.15)$ \\
\hline \multirow[t]{2}{*}{ White } & $0.93^{\mathrm{B}}$ & $0.93^{\mathrm{B}}$ & $0.93^{\mathrm{B}}$ & $0.93^{\mathrm{B}}$ \\
\hline & $(0.85,1.01)$ & $(0.85,1.01)$ & $(0.85,1.01)$ & $(0.85,1.01)$ \\
\hline Race/Ethnicity & $\mathrm{X}$ & $\mathrm{X}$ & $\mathrm{X}$ & $\mathrm{X}$ \\
\hline Life Course Characteristics & & $X$ & $X$ & $X$ \\
\hline Spatial Characteristics & & & $X$ & $X$ \\
\hline Socioeconomic Characteristics & & & & $\mathrm{X}$ \\
\hline
\end{tabular}

Notes: $\mathrm{N}=2,029$. Estimates are presented as predicted means from weighted Poisson regression models. 95\% confidence intervals are reported in parentheses. Superscript letters denote estimates that are statistically distinguishable from respondents who identified as ${ }^{\mathrm{B}}$ Black, ${ }^{\mathrm{H}}$ Hispanic, ${ }^{\mathrm{O}}$ Other, and ${ }^{\mathrm{W}}$ White race/ethnicity at the 95 -percent confidence level. 